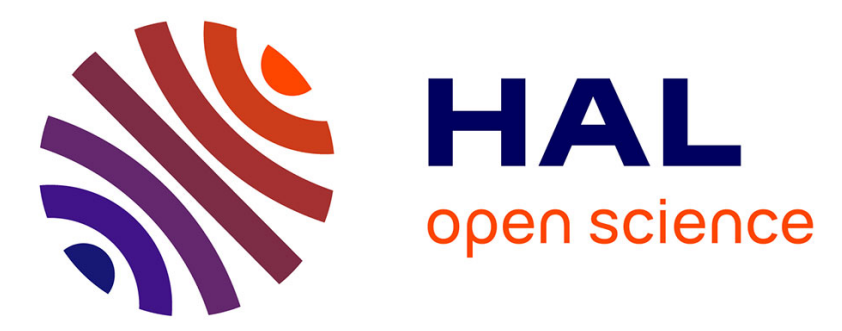

\title{
Asymmetric 1,3-Dipolar Cycloadditions of Cyclic Stabilized Ylides Derived from Chiral 1,2-Amino Alcohols
}

Martine Bonin, Laurent Micouin, Ariane Chauveau

\section{To cite this version:}

Martine Bonin, Laurent Micouin, Ariane Chauveau. Asymmetric 1,3-Dipolar Cycloadditions of Cyclic Stabilized Ylides Derived from Chiral 1,2-Amino Alcohols. SYNLETT, 2006, 2006 (15), pp.2349-2363. 10.1055/s-2006-949626 . hal-02185347

\section{HAL Id: hal-02185347 \\ https://hal.science/hal-02185347}

Submitted on 16 Jul 2019

HAL is a multi-disciplinary open access archive for the deposit and dissemination of scientific research documents, whether they are published or not. The documents may come from teaching and research institutions in France or abroad, or from public or private research centers.
L'archive ouverte pluridisciplinaire HAL, est destinée au dépôt et à la diffusion de documents scientifiques de niveau recherche, publiés ou non, émanant des établissements d'enseignement et de recherche français ou étrangers, des laboratoires publics ou privés. 


\title{
Asymmetric 1,3-Dipolar Cycloadditions of Cyclic Stabilized Ylides Derived from Chiral 1,2-Amino Alcohols
}

\author{
Martine Bonin,* Ariane Chauveau, L. Micouin* \\ Laboratoire de Chimie Thérapeutique, UMR 8638 associée au CNRS, Université René Descartes, Faculté des Sciences Pharmaceutiques \\ et Biologiques, 4 av de l'Observatoire, 75270 Paris cedex 06, France \\ Fax+33(1)43291403; E-mail: laurent.micouin@univ-paris5.fr; E-mail: martine.bonin@intas.be \\ Received 2 March 2006
}

\begin{abstract}
The use of structurally similar chiral non-racemic azomethine ylides, nitrones and azomethine imines derived from 1,2 -aminol alcohols in asymmetric dipolar cycloadditions is reviewed. This general survey underlines the great synthetic potential of dipolar cycloadditions, especially in a diversity-oriented approach and enables a direct comparison of the reactivity of apparently closely related reactive systems.

1 Introduction

2 Azomethine Ylides

2.1 Reactions Involving Ylides Derived from Formaldehyde

2.2 Reactions Involving Ylides Derived from Aliphatic or Aromatic Aldehydes

2.3 Reactions Involving Ylides Derived from Alkyl Glyoxylates or Ketones

2.4 Synthetic Applications

3 Nitrones

3.1 Reactions with Alkenes

3.2 Synthetic Applications

4 Azomethine Imines

$4.1 \quad$ Ylide Generation

4.2 Reactions Involving Ylides Derived from Aliphatic or Aromatic Aldehydes

4.3 Reactions Involving Ylides Derived from Alkyl Glyoxylates

4.4 Synthetic Applications

5 Conclusion
\end{abstract}

Key words: cycloadditions, ylides, stereoselective synthesis, heterocycles, multicomponent reactions

\section{$1 \quad$ Introduction}

The power of multicomponent reactions (MCRs) as diversity-generating processes for the convergent preparation of combinatorial libraries of compounds having interesting chemical, physical, or biological properties is nowadays widely recognized. ${ }^{1}$ In this context, [3+2] cycloadditions are particularly appealing, for numerous reasons: they generally combine three widely available classes of compounds (i.e. aldehydes, amines and alkenes), with a good functional group tolerance, under experimentally simple reaction conditions (generally thermal, aerobic conditions) leading to cyclic rigid func-

SYNLETT 2006, No. 15, pp 2349-2363

Advanced online publication: 08.09.2006

DOI: 10.1055/s-2006-949626; Art ID: A41606ST

(c) Georg Thieme Verlag Stuttgart · New York tionalized heterocycles in a very convergent manner with limited side reactions. ${ }^{2}$

One more advantage of the 1,3-dipolar cycloaddition reaction is its high stereospecificity, leading to the creation of up to four stereocenters in a single operation. Furthermore, an appropriate set of reaction conditions and reagents enables, in principle, the tuning of relative configuration of the final cycloadduct by controlling the reactive configuration of the reaction partners. ${ }^{3}$ This stereochemical diversity is a key element if one wishes to use asymmetric multicomponent reactions in diversity-oriented syntheses. ${ }^{4}$

Several parameters are responsible for the stereochemical outcome of a 1,3-dipolar cycloaddition (Scheme 1). The configuration of stereocenters a and $\mathrm{c}$ will be determined by the configuration of the reactive dipole [with syn (anti) dipoles leading to $\mathrm{R}^{1}, \mathrm{R}^{2}$ syn (anti) stereoisomers, respectively) as well as the facial selectivity of the reaction. The relative configuration between stereocenters $\mathrm{d}$ and $\mathrm{e}$ is determined by the configuration of the double bond in its reactive form, the relative a,d or c,e configurations being determined by the facial as well as the endo-exo selectivities. All these rules, of course, only apply provided that the condensation occurs in a concerted manner, delivering a non-epimerizable final cycloadduct.

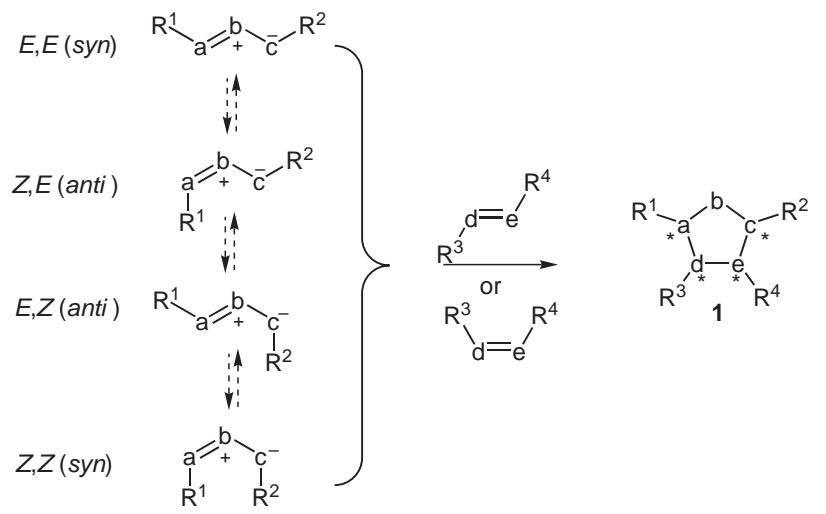

Scheme 1 General five-membered-ring synthesis by a dipolar [3+2] cycloaddition process.

As depicted in Scheme 1, a mixture of stereoisomers can be expected from a cycloaddition based on configurationally labile dipoles, unless an efficient dynamic resolution can occur. The incorporation of the $a-b$ or $b-c$ bond of the 
ylide into a cyclic, rigid element has therefore been proposed in order to increase rotational barriers in these reactive species. Furthermore, the use of a chiral tether in such a strategy should enable the control of the facial selectivity, leading to the control of the relative and absolute configuration of centers a and $\mathrm{c}$ of $\mathbf{1}$.

In a general research project on the use of cyclic hydrazines for the synthesis of polyfunctional amines, ${ }^{5}$ we were particularly interested by works reporting stereoselective dipolar cycloadditions of azomethine ylides ${ }^{6}$ and nitrones ${ }^{7}$ using similar cyclic templates derived from a common morpholinone (Figure 1). The apparent excellent facial selectivities prompted us to investigate such cyclic precursors in the azomethine imine series. In this account the<smiles>[R]C=[N+]1CC(=O)OC([Y])[C@H]1c1ccccc1</smiles><smiles>O=C1C=[N+]([O-])[C@H](c2ccccc2)CO1</smiles><smiles>[R]C=[N+]1[N-]C(=O)OC[C@H]1c1ccccc1</smiles>

Figure 1 Cyclic amino alcohol derived azomethine ylide, nitrones and azomethine imines. use of chiral 1,2-amino alcohols, and more particularly phenylglycinol, as a chiral element in three closely-related cyclic ylides will be discussed.

\section{$2 \quad$ Azomethine Ylides}

Although the use of chiral non-racemic morpholinones in asymmetric transformations had been described since the late sixties, ${ }^{8}$ the first examples of stereoselective cycloadditions of templated azomethine ylides derived from morpholinones were reported by the groups of L. M. Harwood $^{9 a}$ and R. M. Williams ${ }^{10}$ in the early 1990s.

\subsection{Reactions Involving Ylides Derived from Formaldehyde}

\subsubsection{Ylide Generation}

Ylides are typically generated by condensation of the morpholinones 5-7 with an excess of paraformaldehyde under thermal activation in the presence of molecular

\section{Biographical Sketches}
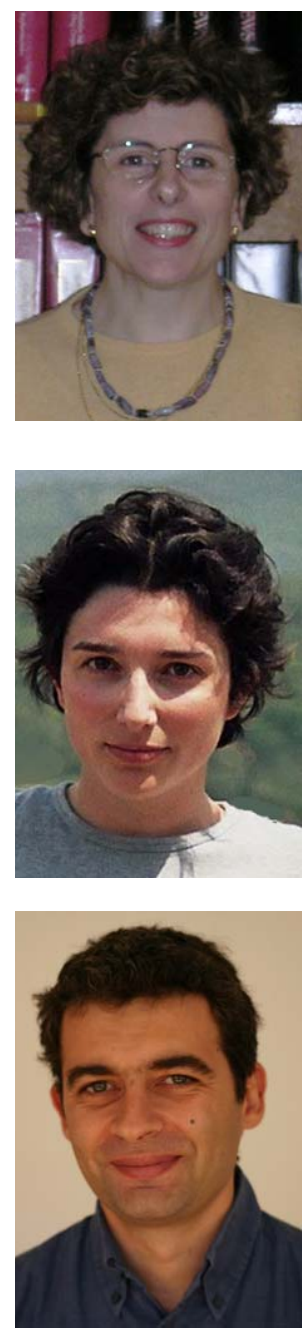

Martine Bonin was born in 1957. She trained as a pharmacist in the University of Bordeaux (1979), and obtained her PhD in Chemistry from the University of Paris-Sud (Orsay) in 1986 on the total synthesis of piperidine alkaloids. Enlisted as researcher in CNRS in Professor Henri-Philippe Hus-

Ariane Chauveau was born in 1977. She was trained as a chemist at the Ecole Na- son's group (1983), she began collaboration with Dr. J.-C. Quirion on aminonitrile and oxazolidine synthons and followed that with a one-year postdoc in Orsay (Drs. G. Balavoine and F. Guibe, organometallic and radical chemistry, 1992). From 1998, she worked with Dr. Laurent Micouin tionale Supérieure de Chimie de Paris and received her engineer diploma in on the development of new diastereoselective routes giving access to polyfunctional nitrogen derivatives for medicinal or pharmacological applications. She then took a project manager position at the INTAS organization in Brussels in 2004.

1999. She obtained her PhD on azomethine imine cycloadditions reactions in 2003.
Laurent Micouin was born in Clermont Ferrand in 1968. He studied at the Ecole Nationale Supérieure de Chimie de Paris, where he obtained an engineer diploma in 1990. He obtained his $\mathrm{PhD}$ in the laboratory of Professor Henri-Philippe Husson (University Paris V) under the guidance of Pro- fessor J.-C. Quirion in 1995. After a postdoctoral stay in Marburg (Germany) as a Humboldt Fellow under the direction of Professor Paul Knochel, he got a permanent position in CNRS in 1996 and returned to Paris (Faculty of Pharmacy, Paris V) as Chargé de Recherche, and, since October 2005, as
Directeur de Recherche. His scientific interests include the development of new methods in the field of asymmetric synthesis of nitrogen compounds, organoaluminum chemistry, as well as the development of new tools in the field of fragment-based approach for the discovery of bioactive compounds. 
sieves, ${ }^{9 a, b}$ or in the presence of a catalytic amount of $p$-toluenesulfonic acid at room temperature over extended periods. ${ }^{10 a}$ Due to their high reactivity, these species are trapped in situ by the dipolarophiles, generally used in excess. Another procedure involves the use of stable precursors, such as alkoxy amines $\mathbf{2}-\mathbf{4},{ }^{10 a}$ hemi-aminal $\mathbf{8}^{11}$ or aminobenzotriazole 9 derivatives, ${ }^{12}$ which can regenerate the ylide under acidic or thermal conditions (Scheme 2).
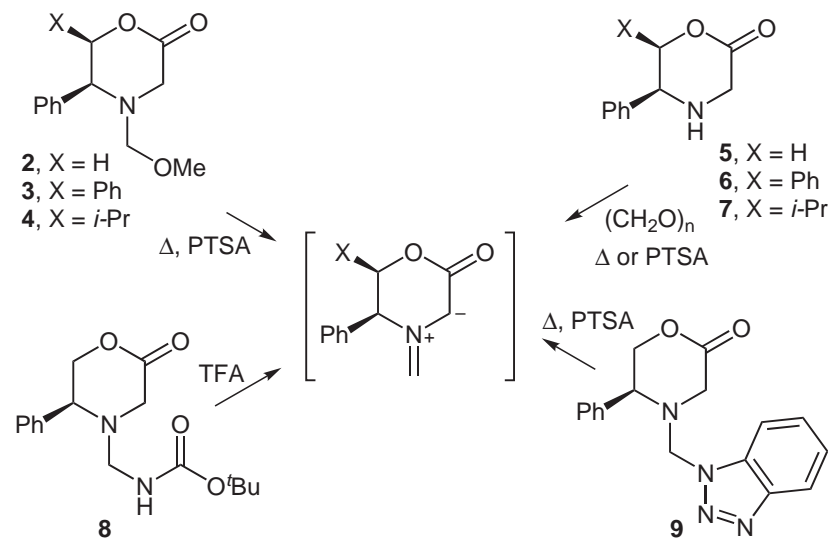

Scheme 2 Ylide generation from morpholinones.

\subsubsection{Reactions with Alkynes}

Alkynes are mechanistically useful dipolarophiles since they can lead to only two possible diastereomers with formaldehyde-derived dipoles. The stereochemical issue of the cycloaddition is therefore directly related to the facial selectivity, and provides a way to evaluate the chirality transfer from the morpholinone.

Thus, use of a symmetrical electron-deficient alkyne resulted in a single cycloadduct $\mathbf{1 0}$, and only one regioisomer could be obtained stereoselectively from methylpropynoate (Scheme 3). ${ }^{9 a, 13}$ A better yield (56\%) of compound 11 could be obtained when conducting the reaction under Lewis acid assistance (1.1 equiv of dipolarophile, excess of freshly prepared $\mathrm{MgBr}_{2} \cdot \mathrm{OEt}_{2}$, refluxing THF). ${ }^{14}$ These results clearly indicate that the facial 'steric' selectivity is perfectly controlled with phenylglycinol as a chiral tether in azomethine ylide cycloadditions.

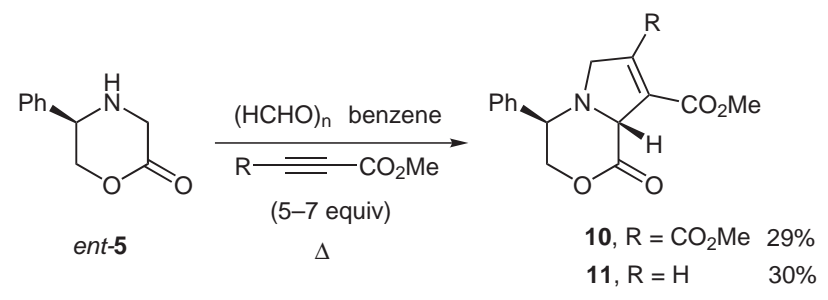

Scheme 3 Cycloadditions with activated alkynes.

\subsubsection{Reactions with Alkenes}

Doubly activated alkenes react generally well with azomethine ylides, delivering cycloadducts in good chemical yields (Table 1)..$^{\text {aa,b,10a,15 }}$
In all the cases, complete facial selectivity has been observed, and the endo cycloadduct was isolated as a major diastereomer under thermal activation. When conducted in the presence of $\mathrm{MgBr}_{2} \cdot \mathrm{OEt}_{2}$, the cycloaddition led to the exo adduct as either the major product (entries 4 and 11 ) or almost exclusively (entries 5 and 8). All the reactions performed on acyclic dipolarophiles were fully stereospecific (entries 4 and 5).

Although the one-pot methodology is a simple process, the generation of the reactive ylide from a stable precursor generally provides a way to obtain cycloadducts in superior yields (Scheme 4), ${ }^{10 a, 12}$ and avoids the sometimes troublesome use of a large excess of paraformaldehyde. In all cases, the stereochemical issue is similar to the one-pot procedure, showing that the same reactive intermediate is generated.

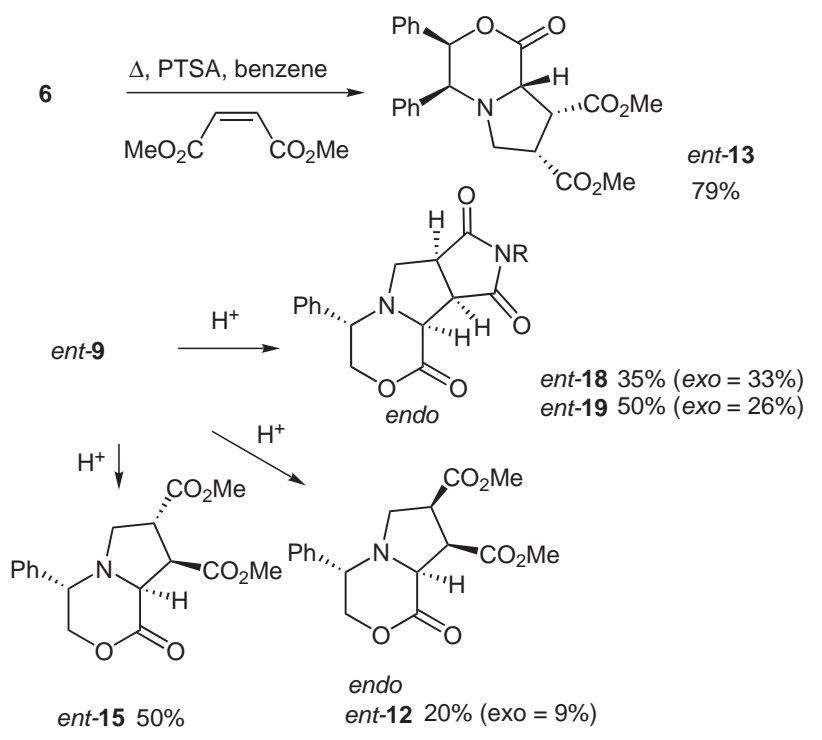

Scheme 4 Cycloadditions from stable ylides precursors.

Singly activated alkenes are much less reactive dipolarophiles, as depicted in Scheme 5. ${ }^{16}$ All the cyclic dipolarophiles led to the predominant formation of exo-addition products with almost complete regioselectivity; whereas the use of acyclic dipolarophiles had been reported to result in failure to isolate cycloadducts under thermal conditions, except with phenylsulfone when the major isomer was found to be the endo-cycloadduct 27 with only traces of the exo-diastereomer being detected. However, methyl acrylate and acrylonitrile have been reported to react with the ylide under Lewis acid activation, leading to complementary regiocontrol, in a low diastereoselectivity. 'Unactivated alkenes' are generally considered to be poorly reactive in intermolecular 1,3-dipolar cycloadditions involving stabilized azomethine ylides. Thus, the reaction with cis- or trans-stilbene gave particularly low yields of the corresponding adducts $\mathbf{2 3}$ and $\mathbf{2 4}$. 
Table 1 Reaction of Azomethine Ylides with Doubly Activated Alkenes ${ }^{\mathrm{a}}$

\begin{tabular}{|c|c|c|c|c|c|c|c|c|c|}
\hline \multirow[t]{2}{*}{ Entry } & \multirow[t]{2}{*}{$\mathrm{R}$} & \multirow[t]{2}{*}{ Dipolarophile } & \multirow[t]{2}{*}{ Method } & \multicolumn{3}{|l|}{ Adduct } & \multicolumn{3}{|c|}{$\begin{array}{l}\text { endo exo } \\
\text { (isolated yield, \%)(isolated yield, \%) }\end{array}$} \\
\hline & & & & $X$ & $\mathrm{Y}$ & $\mathrm{Z}$ & & & \\
\hline 1 & $\mathrm{H}$ & $\mathrm{MeO}_{2} \mathrm{C}$ & A & $\mathrm{CO}_{2} \mathrm{Me}$ & $\mathrm{CO}_{2} \mathrm{Me}$ & $\mathrm{H}$ & 20 & 6 & 12 \\
\hline 2 & $\mathrm{Ph}$ & $\mathrm{MeO}_{2} \mathrm{C}^{\prime}$ & B & $\mathrm{CO}_{2} \mathrm{Me}$ & $\mathrm{CO}_{2} \mathrm{Me}$ & $\mathrm{H}$ & 39 & b & 13 \\
\hline 3 & $i-\operatorname{Pr}$ & $\mathrm{MeO}_{2} \mathrm{C}^{\prime}$ & $\mathrm{C}$ & $\mathrm{CO}_{2} \mathrm{Me}$ & $\mathrm{CO}_{2} \mathrm{Me}$ & $\mathrm{H}$ & 34 & c & 14 \\
\hline 4 & $\mathrm{H}$ & $\mathrm{MeO}_{2} \mathrm{C}^{\prime}$ & $\mathrm{D}$ & $\mathrm{CO}_{2} \mathrm{Me}$ & $\mathrm{CO}_{2} \mathrm{Me}$ & $\mathrm{H}$ & 40 & 20 & 12 \\
\hline 5 & $\mathrm{H}$ & $\mathrm{MeO}$ & $\mathrm{D}$ & $\mathrm{CO}_{2} \mathrm{Me}$ & $\mathrm{H}$ & $\mathrm{CO}_{2} \mathrm{Me}$ & 0 & 52 & 15 \\
\hline 6 & $\mathrm{H}$ & & A & \multicolumn{3}{|c|}{$\mathrm{CON}(\mathrm{H}) \mathrm{CO}$} & 54 & - & 16 \\
\hline 7 & $\mathrm{H}$ & & A & \multicolumn{3}{|c|}{$\mathrm{CON}(\mathrm{Me}) \mathrm{CO}$} & 41 & 19 & 17 \\
\hline 8 & $\mathrm{H}$ & & $\mathrm{D}$ & \multicolumn{3}{|c|}{$\mathrm{CON}(\mathrm{Me}) \mathrm{CO}$} & $<1$ & 80 & 17 \\
\hline 9 & $i-\operatorname{Pr}$ & & $\mathrm{C}$ & \multicolumn{3}{|c|}{$\mathrm{CON}(\mathrm{Me}) \mathrm{CO}$} & 58 & d & 18 \\
\hline 10 & $\mathrm{H}$ & & A & \multicolumn{3}{|c|}{$\mathrm{CON}(\mathrm{Ph}) \mathrm{CO}$} & 45 & 13 & 19 \\
\hline 11 & $\mathrm{H}$ & & $\mathrm{D}$ & \multicolumn{3}{|c|}{$\mathrm{CON}(\mathrm{Ph}) \mathrm{CO}$} & 9 & 54 & 19 \\
\hline 12 & $\mathrm{H}$ & & A & \multicolumn{3}{|c|}{$\mathrm{COOCO}$} & 49 & - & 20 \\
\hline
\end{tabular}

${ }^{a}$ Method A: excess (HCHO) $)_{n}, 3-7$ equiv dipolarophile, benzene, 3 A MS, reflux. Method B: excess (HCHO), 3 equiv dipolarophile, PTSA, benzene, r.t. Method C: excess $(\mathrm{HCHO})_{\mathrm{n}}, 5$ equiv dipolarophile, toluene, $80^{\circ} \mathrm{C}$. Method D: 5 equiv $(\mathrm{HCHO})_{\mathrm{n}}, 1.1$ equiv dipolarophile, excess $\mathrm{MgBr}_{2} \cdot \mathrm{OEt}_{2}$, THF, reflux.

${ }^{\mathrm{b}}$ The amount of the exo stereoisomer was not reported.

${ }^{c}$ The endolexo ratio in the crude reaction mixture was $85: 8$.

${ }^{\mathrm{d}}$ The endo/exo ratio in the crude reaction mixture was 55:25.

\subsection{Reactions Involving Ylides Derived from Aliphatic or Aromatic Aldehydes}

\subsubsection{Reactions with Alkenes}

The use of higher aldehydes in cycloadditions can lead to a more complex situation. The additional substituent on the ylide will not only introduce a new stereogenic element, but can also tune the general reactivity of the ylides, as well as the FMO-related stereocontrol.
In fact, four of the eight possible cycloadducts were obtained in the reaction involving benzaldehyde and $N$-methyl maleimide (Scheme 6). ${ }^{13}$ A similar observation was made in the diphenylmorpholinone series (Table 2). ${ }^{10 a}$

Despite total endo selectivity, most of the aldehydes led to an almost equimolar ratio of C-7 epimers. Interestingly, the use of isobutyraldehyde led to the stereoselective formation of $\mathbf{3 4}$ as a single adduct. This excellent stereo- 


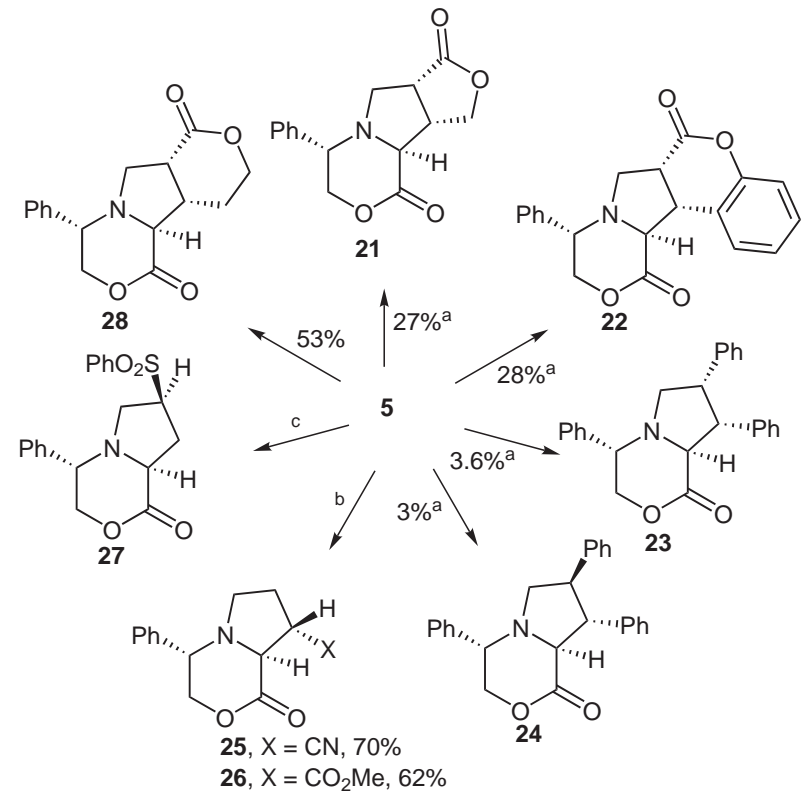

Scheme 5 Cycloadditions with mono- or non-activated alkenes. Reagents and conditions: (a) $(\mathrm{CHO})_{\mathrm{n}}(10$ equiv), dipolarophile (7 equiv), benzene, reflux, MS $3 \AA$ A (b) $(\mathrm{CHO})_{\mathrm{n}}$ (5 equiv), dipolarophile (1.1 equiv), $\mathrm{MgBr}_{2} \mathrm{Et}_{2} \mathrm{O}$ (excess), THF, reflux, MS $3 \AA ; 0 \%$ de for $\mathrm{X}=\mathrm{CN}, 35 \%$ de for $\mathrm{X}=\mathrm{CO}_{2} \mathrm{Me}$; (c) thermal conditions, yield not given.

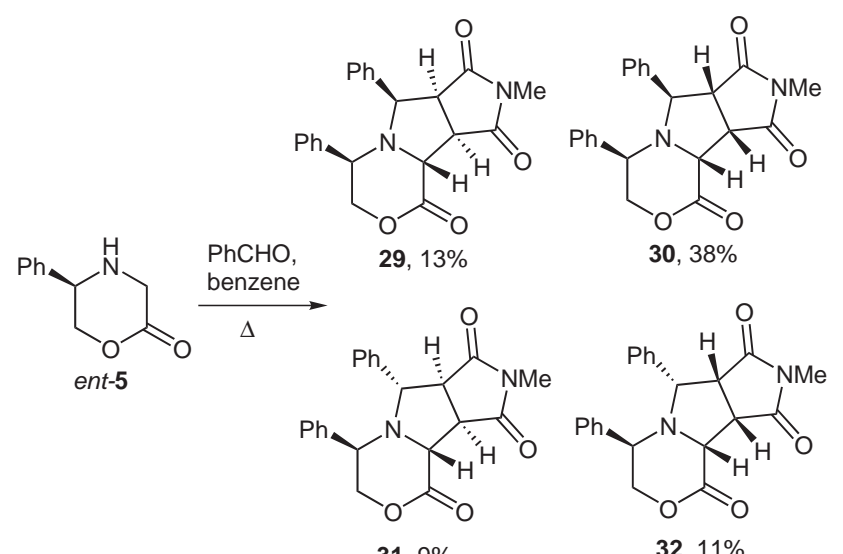

Scheme 6 Reaction of ylide derived from benzaldehyde and doubly activated dipolarophiles.

selectivity with branched aldehydes has led recently to a very powerful method for the synthesis of spirooxindole derivatives (Table 3 ). ${ }^{17}$ This highly exo-selective reaction that can establish in a single operation four contiguous stereogenic centers, including the quaternary center, has found several applications in the total synthesis of natural products (see part 2.4).

\subsubsection{Reactions with Aldehydes or Imines}

A typical side product that can be obtained in the one-pot procedure is the reaction of the ylide with a second molecule of aldehyde. This reaction has been exploited for the synthesis of $\beta$-hydroxy- $\alpha$-amino acids (Table 4$).{ }^{18}$

In all cases, cycloadducts were isolated in good to excellent yields as single diastereoisomers. Aliphatic aldehydes
Table 2 Reaction of Branched Azomethine Ylides with Dimethylmaleate

\begin{tabular}{lllll} 
Entry $^{\mathrm{a}}$ & Aldehyde & $\mathrm{Yield}(\%)$ & $\mathrm{dr}$ & $\mathrm{Compd}$ \\
\hline 1 & Propionaldehyde & 32 & $1.33: 1$ & $\mathbf{3 3}$ \\
2 & Isobutyraldehyde & 52 & $1: 0^{\mathrm{b}}$ & $\mathbf{3 4}$ \\
3 & Benzaldedhyde & 70 & $1.7: 1$ & $\mathbf{3 5}$ \\
4 & $p$-Anisaldehyde & 71 & $1: 1$ & $\mathbf{3 6}$ \\
5 & $p$-Nitrobenzaldehyde & 71 & $1: 1$ & $\mathbf{3 7}$ \\
6 & 2-Furaldehyde & 61 & $1: 1$ & $\mathbf{3 8}$
\end{tabular}

${ }^{a}$ Reaction conditions : Aldehyde (1.4 equiv), dipolarophile ( 3.5 equiv), PTSA (0.4 equiv), benzene, reflux.

$\mathrm{b}$ The all-syn stereoisomer was obtained.

Table 3 Stereoselective Formation of Spirocyclic Indolinones

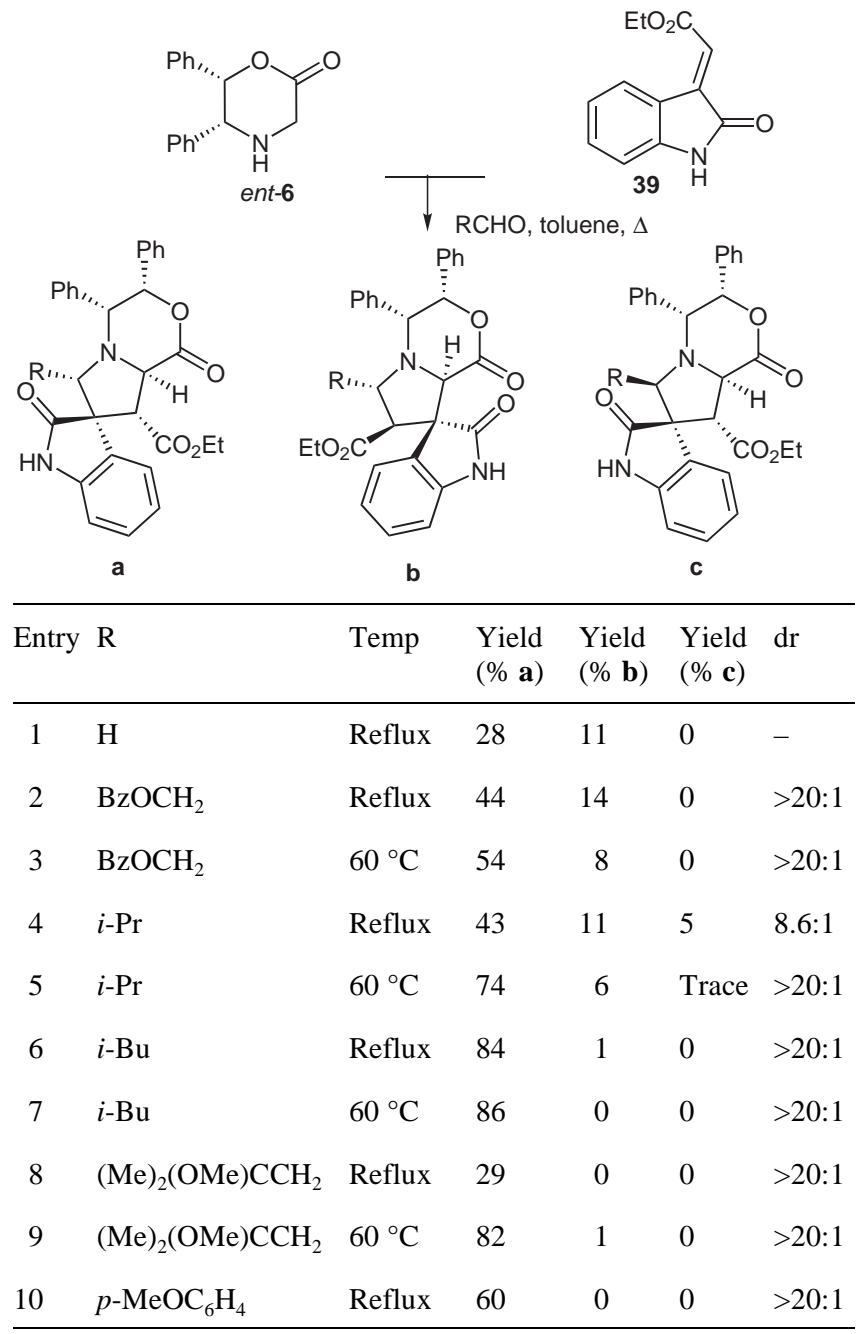


Table 4 Reaction of Azomethine Ylides with Aldehydes ${ }^{\mathrm{a}}$

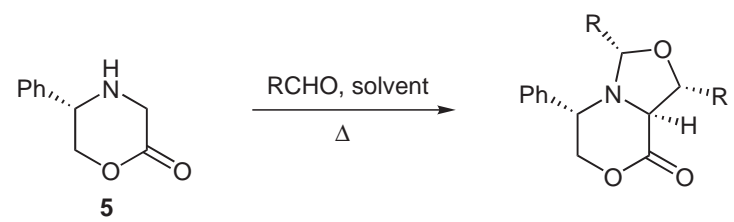

\begin{tabular}{lllll}
\hline Entry & $\mathrm{R}$ & Solvent & Yield (\%) & Compd \\
\hline 1 & $\mathrm{Ph}$ & Toluene & 69 & $\mathbf{4 0}$ \\
2 & $p-\mathrm{FC}_{6} \mathrm{H}_{4}$ & Toluene & 61 & $\mathbf{4 1}$ \\
3 & $p-\mathrm{NO}_{2} \mathrm{C}_{6} \mathrm{H}_{4}$ & Toluene & 45 & $\mathbf{4 2}$ \\
4 & $p-\mathrm{MeOC}_{6} \mathrm{H}_{4}$ & Toluene & 50 & $\mathbf{4 3}$ \\
5 & $2-\mathrm{Furyl}$ & Toluene & 51 & $\mathbf{4 4}$ \\
6 & $\mathrm{Pr}$ & Benzene & 86 & $\mathbf{4 5}$ \\
7 & $\mathrm{Bu}$ & Benzene & 80 & $\mathbf{4 6}$ \\
8 & Cyclohexyl & Toluene & 80 & $\mathbf{4 7}$ \\
\hline
\end{tabular}

${ }^{a}$ Reaction conditions: aldehyde ( 3 equiv), toluene, $3 \AA$ MS, reflux.

are particularly reactive in this transformation (entries 6 8). ${ }^{19}$ It is interesting to note that the yilde generated from benzaldehyde (entry 1) led to a single adduct, whereas the same reactive intermediate reacted with $N$-methylmaleimide in a non-stereoselective manner (Scheme 6).

A similar approach has been conducted with imines, leading to the stereoselective construction of threo-2,3-diamino acids (Table 5). The use of acidic conditions proved to be essential for ylide generation via a trans-imination step. $^{20}$

Table 5 Reaction of Azomethine Ylides with Imines ${ }^{\mathrm{a}}$

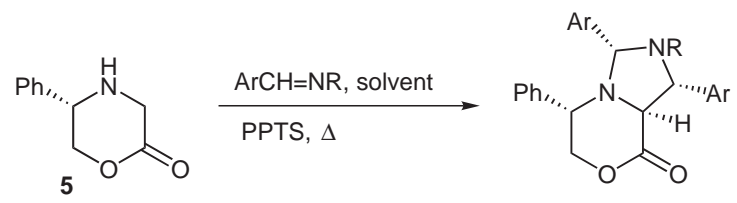

\begin{tabular}{lllll}
\hline Entry & $\mathrm{Ar}$ & $\mathrm{R}$ & Yield (\%) & Compd \\
\hline 1 & $\mathrm{Ph}$ & $\mathrm{Me}$ & 69 & $\mathbf{4 8}$ \\
2 & $\mathrm{Ph}$ & $\mathrm{Bn}$ & 61 & $\mathbf{4 9}$ \\
3 & $p-\mathrm{MeOC}_{6} \mathrm{H}_{4}$ & $\mathrm{Bn}$ & 45 & $\mathbf{5 0}$ \\
4 & $p-\mathrm{NO}_{2} \mathrm{C}_{6} \mathrm{H}_{4}$ & $\mathrm{Bn}$ & 50 & $\mathbf{5 1}$ \\
5 & $p-\mathrm{FC}_{6} \mathrm{H}_{4}$ & $\mathrm{Bn}$ & 51 & $\mathbf{5 2}$ \\
\hline
\end{tabular}

${ }^{\text {a }}$ Reaction conditions: imine ( 3 equiv), PPTS, 3 Å MS, reflux.

\subsection{Reactions Involving Ylides Derived from Alkyl Glyoxylates or Ketones}

Interesting substituted proline precursors can be obtained when using ethyl glyoxylate as the aldehydic partner in dipolar cycloadditions (Scheme 7).

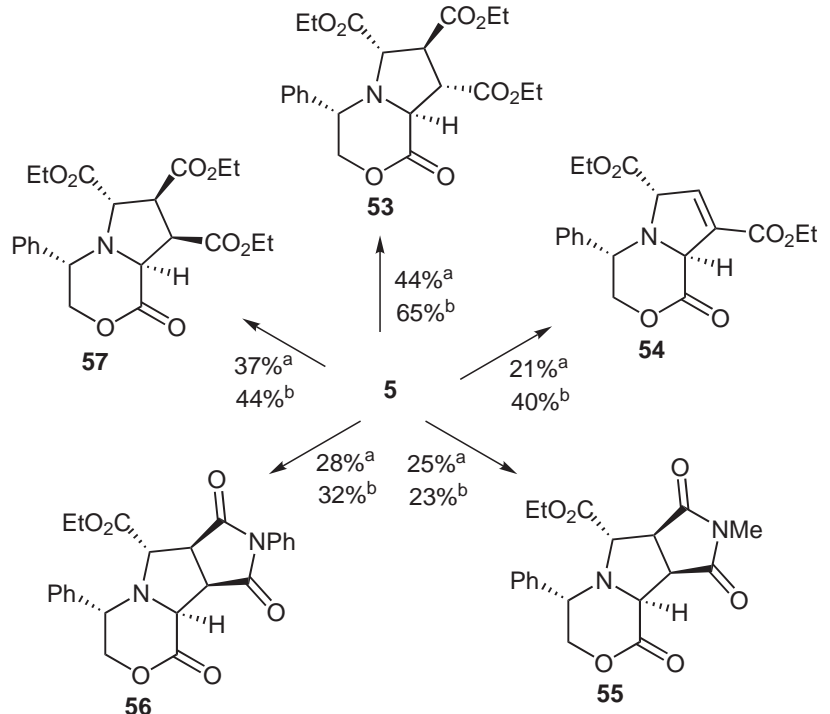

Scheme 7 Reagents and conditions: (a) ethyl glyoxalate trimer, dipolarophile, toluene, MS, reflux; (b) ethyl glyoxalate trimer, dipolarophile, $\mathrm{MgBr}_{2} \cdot \mathrm{OEt}_{2}$, THF, r.t.

The reaction can be conducted under thermal or Lewis acidic conditions. In the latter case, both chemical yields and, where appropriate, exo-isomer proportion, were increased. ${ }^{21}$

Ketones are not usually ylide precursors, probably because of their reduced electrophilicity and the allylic strain created during the formation of the dipole. The formation of cycloadducts bearing a quaternary center $\alpha$ to the nitrogen atom could, however, be achieved from a transient tetrahedral precursor (Table 6). ${ }^{22}$

In all the cases the major diastereomer was the endo adduct, although the selectivity was relatively poor with symmetrical $Z$ alkenes (entries 1-3). Monoactivated

Table 6 Cycloadditions with Ketone-Derived Azomethine Ylides ${ }^{\mathrm{a}}$
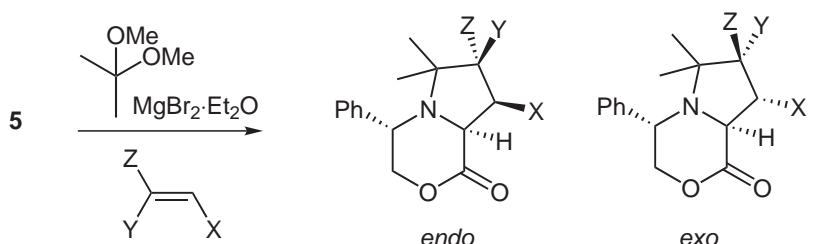

endo

exo

\begin{tabular}{|c|c|c|c|c|c|c|}
\hline Entry & $\mathrm{X}$ & $\mathrm{Y}$ & $\mathrm{Z}$ & endo $(\%)$ & $\operatorname{exo}(\%)$ & Compd \\
\hline 1 & \multicolumn{2}{|c|}{$(\mathrm{CO}) \mathrm{NPh}(\mathrm{CO})$} & $\mathrm{H}$ & 43 & 30 & 58 \\
\hline 2 & \multicolumn{2}{|c|}{$(\mathrm{CO}) \mathrm{NMe}(\mathrm{CO})$} & $\mathrm{H}$ & 33 & 26 & 59 \\
\hline 3 & $\mathrm{CO}_{2} \mathrm{Me}$ & $\mathrm{CO}_{2} \mathrm{Me}$ & $\mathrm{H}$ & 23 & 16 & 60 \\
\hline 4 & $\mathrm{CO}_{2} \mathrm{Me}$ & & $\mathrm{CO}_{2} \mathrm{Me}$ & 70 & 0 & 61 \\
\hline 5 & $\mathrm{H}$ & $\mathrm{CO}_{2} \mathrm{Me}$ & $\mathrm{H}$ & 14 & 0 & 62 \\
\hline 6 & $\mathrm{H}$ & $\mathrm{CN}$ & $\mathrm{H}$ & 40 & 0 & 63 \\
\hline
\end{tabular}

${ }^{\text {a }}$ Reaction conditions: 2,2-dimethoxypropane (2 equiv), $\mathrm{MgBr}_{2} \cdot \mathrm{OEt}_{2}$, dipolarophile ( 2 equiv), THF, reflux. 
Table 7 Cycloadditions with Benzophenone-Derived Azomethine Ylides $^{\mathrm{a}}$

5
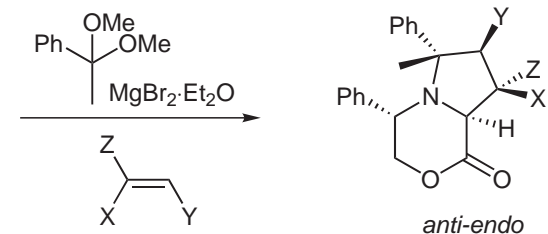

anti-endo

\begin{tabular}{llllcl}
\hline Entry & $\mathrm{X}$ & $\mathrm{Y}$ & $\mathrm{Z}$ & endo $(\%)$ & Compd \\
\hline 3 & $\mathrm{CO}_{2} \mathrm{Me}$ & $\mathrm{CO}_{2} \mathrm{Me}$ & $\mathrm{H}$ & 8 & $\mathbf{6 4}$ \\
4 & $\mathrm{H}$ & $\mathrm{CO}_{2} \mathrm{Me}$ & $\mathrm{H}$ & 43 & $\mathbf{6 5}$ \\
5 & $\mathrm{H}$ & $\mathrm{CN}$ & $\mathrm{H}$ & 20 & $\mathbf{6 6}$ \\
6 & $\mathrm{H}$ & $\mathrm{CO}_{2} \mathrm{Me}$ & $\mathrm{H}$ & 38 & $\mathbf{6 7}$ \\
\hline
\end{tabular}

${ }^{\mathrm{a}}$ Reaction conditions: acetophenone dimethylacetal (2 equiv), $\mathrm{MgBr}_{2} \cdot \mathrm{OEt}_{2}$, dipolarophile (3 equiv), THF, reflux.

alkenes reacted in a regio- and stereoselective manner (entries 5, 6).

The use of unsymmetrical ketones can theoretically lead to a complex stereochemical issue. However, except with maleimide dipolarophiles, only the anti-endo cycloadducts could be isolated from the reaction mixture (Table 7). ${ }^{23}$

Interestingly, the use of electron-deficient aldehyde as dipolarophile led chemoselectively to the mixed endo cycloadducts 68, useful precursors of $\beta$-hydroxy- $\alpha$-amino acids (Scheme 8).

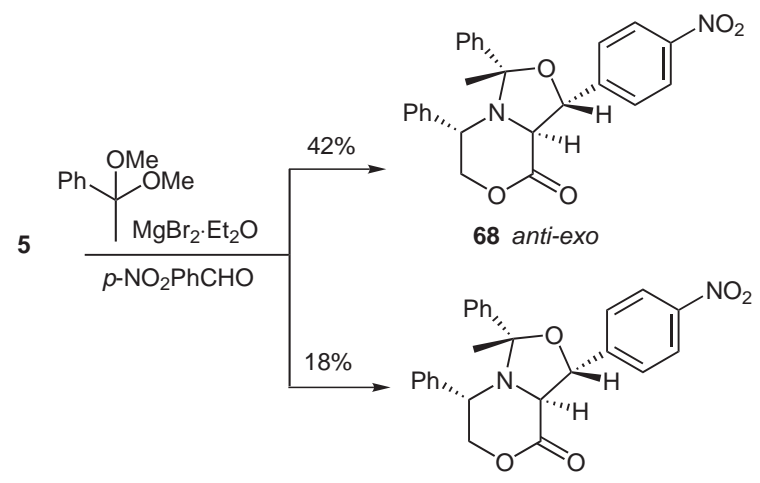

68 syn-exo

Scheme 8 Cycloadditions with electron-deficient aldehyde.

\subsection{Synthetic Applications}

The cycloadducts can be converted to polysubstituted prolines in a straightforward manner. The chiral appendage is classically removed in a single-pot operation by hydrogenolysis with concomitant cleavage of the lactone (Table 8). ${ }^{21,22}$

Acidic conditions are generally required with phenylglycinol-derived morpholinones, whereas the diphenyl-
Table 8 Chiral Appendage Cleavage

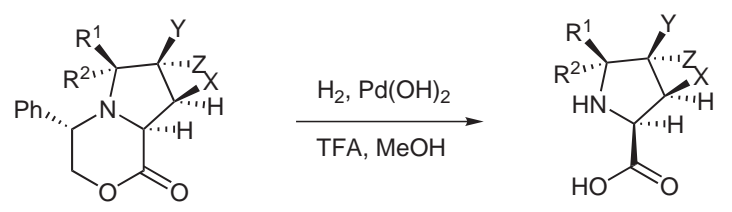

\begin{tabular}{lllllll}
\hline Entry & $\mathrm{R}^{1}$ & $\mathrm{R}^{2}$ & $\mathrm{X}$ & $\mathrm{Y}$ & $\mathrm{Z}$ & Yield (\%) \\
\hline 1 & $\mathrm{Me}$ & $\mathrm{Me}$ & $(\mathrm{CO}) \mathrm{NPh}(\mathrm{CO})$ & $\mathrm{H}$ & 72 \\
2 & $\mathrm{Me}$ & $\mathrm{Me}$ & \multicolumn{2}{c}{$(\mathrm{CO}) \mathrm{NMe}(\mathrm{CO})$} & $\mathrm{H}$ & 71 \\
3 & $\mathrm{Me}$ & $\mathrm{Me}$ & $\mathrm{CO}_{2} \mathrm{Me}$ & $\mathrm{CO}_{2} \mathrm{Me}$ & $\mathrm{H}$ & 65 \\
4 & $\mathrm{Me}$ & $\mathrm{Me}$ & $\mathrm{CO}_{2} \mathrm{Me}$ & $\mathrm{H}$ & $\mathrm{CO}_{2} \mathrm{Me}$ & Quant. \\
5 & $\mathrm{Me}$ & $\mathrm{Me}$ & $\mathrm{H}$ & $\mathrm{CO}_{2} \mathrm{Me}$ & $\mathrm{H}$ & 78 \\
6 & $\mathrm{H}$ & $\mathrm{CO}_{2} \mathrm{Et}$ & $(\mathrm{CO}) \mathrm{NMe}(\mathrm{CO})$ & $\mathrm{H}$ & 85 \\
7 & $\mathrm{H}$ & $\mathrm{CO}_{2} \mathrm{Et}$ & $\mathrm{CO}_{2} \mathrm{Me}$ & $\mathrm{CO}_{2} \mathrm{Me}$ & $\mathrm{H}$ & 90 \\
8 & $\mathrm{H}$ & $\mathrm{CO}_{2} \mathrm{Et}$ & $\mathrm{CO}_{2} \mathrm{Me}$ & $\mathrm{H}$ & $\mathrm{CO}_{2} \mathrm{Me}$ & 75 \\
\hline
\end{tabular}

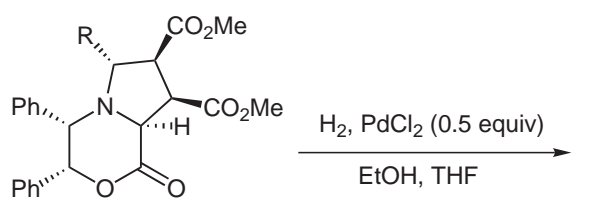<smiles>[R]C1NC(C(=O)O)C(C(C)=O)C1C(C)=O</smiles>

$69, \mathrm{R}=\mathrm{H} 98 \%$ 70, $R=\operatorname{Pr} 93 \%$ $71, \mathrm{R}=i-\mathrm{Bu} 99 \%$

Scheme 9 Access to polysubstituted prolines by hydrogenolysis.

morpholinone is cleaved under 'neutral' conditions (Scheme 9). ${ }^{10 a}$

Despite a milder procedure, sensitive heterocycles such as furans have been reported to be reduced during this step. ${ }^{24}$ Furthermore, the regioselective catalytic hydrogenolysis of adducts bearing two $\mathrm{C}-\mathrm{N}$ benzylic bonds failed. A twostep alternative pathway, involving an oxidative cleavage procedure, has been proposed to overcome these side reactions (Scheme 10). In some cases, epimerization of the amino ester intermediate can occur.<smiles></smiles><smiles>CC(=O)OC(C)=O</smiles>

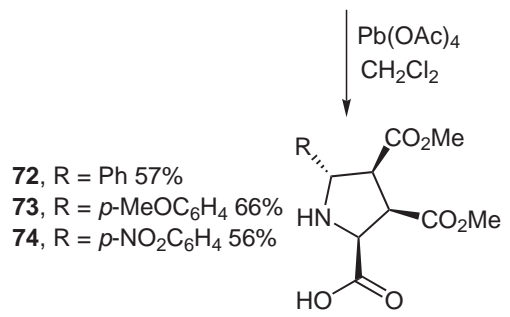

Scheme 10 Access to polysubstituted prolines by oxidative cleavage. 
<smiles>[Z10]C1O[C@@H]([Al])[C@H]2C(=O)OC[C@@H](c3ccccc3)N12</smiles>

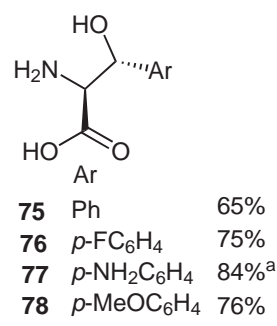

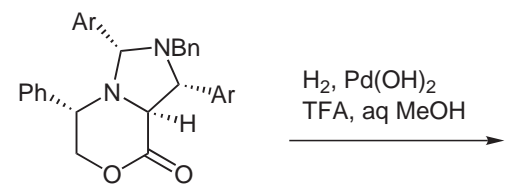<smiles>NC(N)C(N)C(=O)O</smiles>
$79 \mathrm{Ph} \quad 83 \%$ $80 \mathrm{p}-\mathrm{FC}_{6} \mathrm{H}_{4} \quad 64 \%$ $81 p-\mathrm{NH}_{2} \mathrm{C}_{6} \mathrm{H}_{4} \quad 66 \% \%^{\text {a }}$ $82 p-\mathrm{MeOC}_{6} \mathrm{H}_{4} \quad 81 \%$

${ }^{a}$ From the corresponding nitro-precursor<smiles>C=C1CN(CC)CCC1=O</smiles><smiles>CC(C)(C)OC(=O)N1CCC(=O)[C@@]2(C[C@H](C3COC(C)(C)O3)N3[C@H](c4ccccc4)[C@H](c4ccccc4)OC(=O)[C@H]32)C1</smiles>

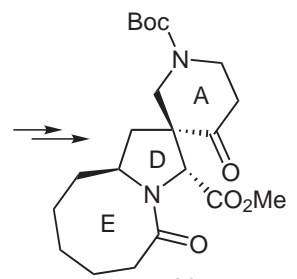

86

Scheme 13 Synthesis of nakadomarin A precursor.

\section{$3 \quad$ Nitrones}

The 1,3-dipolar cycloaddition of nitrones with alkenes can be considered as a useful three-component reaction, since the nitrone itself is easily generated from a hydroxylamine and an aldehyde. However, the stereospecificity of this condensation can be hampered by the known configurational lability of the nitrones. This problem can be avoided by incorporationg the nitrone into a cyclic structure. Although less general, the resulting two-component reaction can, however, deliver very useful synthetic intermediates in a straightforward manner.

Morpholinone-derived nitrones were first reported in the late nineties by the groups of Tamura, Sakamoto, ${ }^{28}$ and Baldwin. ${ }^{29}$ They can be prepared either by the condensation of an hydroxylamine and glyoxylic acid or by the direct oxidation of morpholinone $\mathbf{5}$.

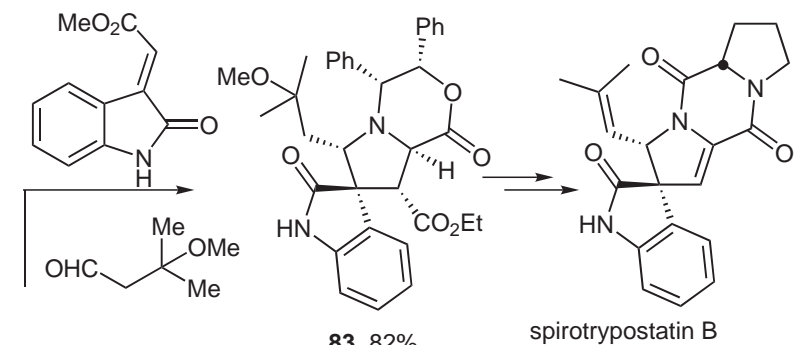

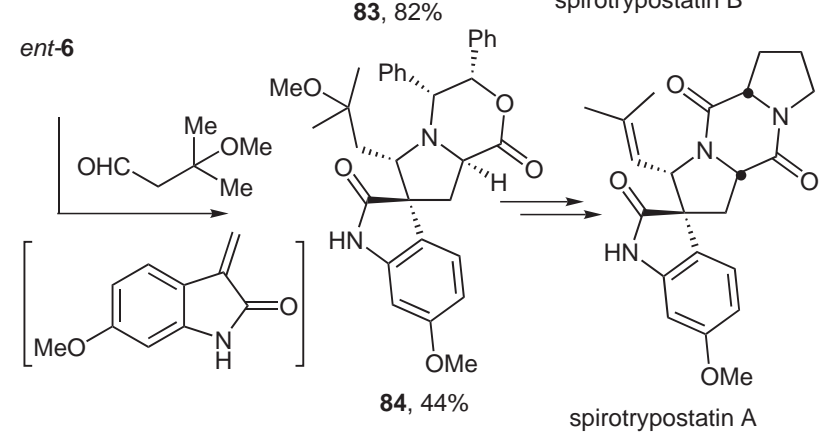

Scheme 12 Synthesis of spirotrypostatin A and B.

The same strategy has also been used for the elaboration of the AD-spirocyclic system of nakadomarin A (Scheme 13). ${ }^{26}$

This rapid and stereoselective construction of polyfunctionnal spirocycles has been recently exploited in the solid-phase-supported diversity-oriented synthesis of libraries of compounds for a chemical genetic program. ${ }^{27}$

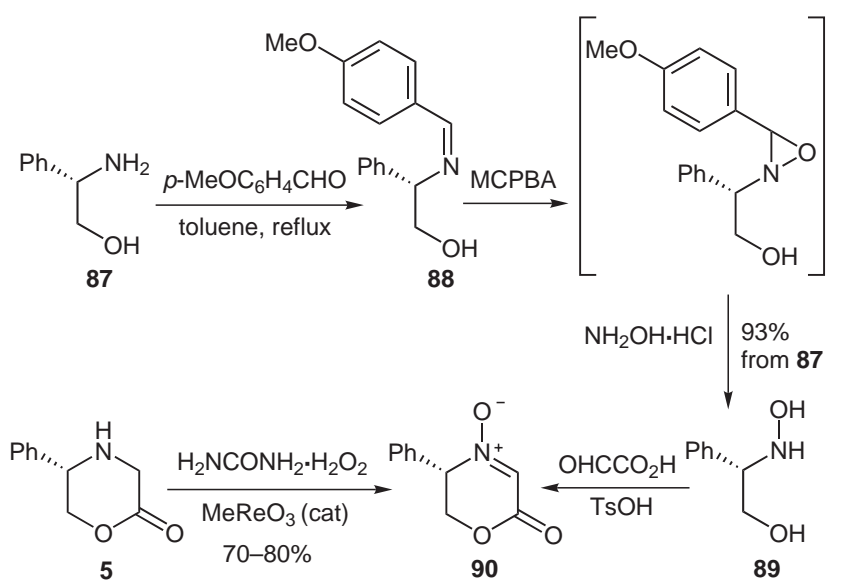

Scheme 14 Synthesis of nitrone 90.

In the latter case, the methyltrioxorhenium/urea-hydrogen peroxide system ${ }^{30}$ appeared to be the best oxidant for the preparation of nitrone $\mathbf{9 0}$ in a reproducible manner on a multigram scale (Scheme 14). ${ }^{31}$ Both methods deliver the nitrone without racemization.

\subsection{Reactions with Alkenes}

Nitrone 90 (or its enantiomer ent-90) reacts at its less-hindered face with linear alkenes in good yields, leading to a 
Table 9 Cycloaddition of Nitrone with Alkenes

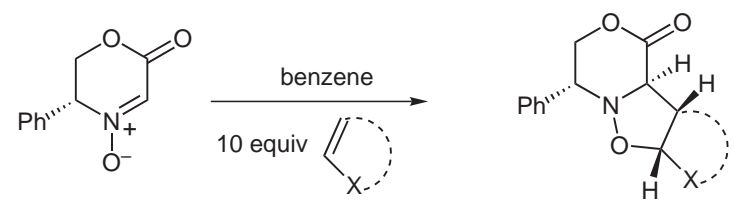

\begin{tabular}{|c|c|c|c|c|}
\hline Entry & Alkene & Conditions & Yield (\%, ratio) & Compc \\
\hline 1 & & r.t., $16 \mathrm{~h}$ & $87(83: 8: 9)$ & 91 \\
\hline 2 & & $60{ }^{\circ} \mathrm{C}, 8 \mathrm{~h}$ & $89(75: 5: 11: 9)$ & 92 \\
\hline $3^{\mathrm{a}}$ & & r.t., $13-20 \mathrm{~h}$ & $>90$ (single isomer) & 93 \\
\hline 4 & & $60^{\circ} \mathrm{C}, 12 \mathrm{~h}$ & $89(75: 5: 11: 9)$ & 94 \\
\hline 5 & & $\begin{array}{l}\text { r.t. to } 50{ }^{\circ} \mathrm{C} \\
19 \mathrm{~h}\end{array}$ & $83(87: 13)$ & 95 \\
\hline $6^{\mathrm{b}}$ & & $60^{\circ} \mathrm{C}, 25 \mathrm{~h}$ & 95 (single isomer) & 96 \\
\hline 7 & & $\begin{array}{l}\text { r.t. to } 50^{\circ} \mathrm{C} \text {, } \\
32 \mathrm{~h}\end{array}$ & 87 (single isomer) & 97 \\
\hline 8 & & r.t., $9 \mathrm{~h}$ & 92 (single isomer) & 98 \\
\hline 9 & & r.t., $30 \mathrm{~h}$ & 90 (single isomer) & 99 \\
\hline 10 & & r.t., $30 \mathrm{~h}$ & $76^{c}(80: 16: 4)$ & 100 \\
\hline
\end{tabular}

${ }^{\text {a }}$ Reaction performed in $\mathrm{CHCl}_{3}$.

${ }^{\mathrm{b}}$ Only 3 equiv of dipolarophile were used.

${ }^{\mathrm{c}}$ Isolated yield of the major isomer.

mixture of diastereoisomers with the exo adduct being the major compound (Table 9, entries $1-4$ ). ${ }^{32}$

A better stereoselectivity has been observed with branched or cyclic alkenes (entries 6-9), delivering a single adduct, with the exception of dihydrofuran (entry 5) and cyclopentadiene (entry 10). A comparative study with a wide range of substituted styrenes has been performed, showing that a remote substituent on the aromatic ring can exert a strong influence on the exolendo ratio (Table 10). ${ }^{33}$

The cycloaddition with allylic alcohols can also be controlled by the presence of $\mathrm{MgBr}_{2} \cdot \mathrm{OEt}_{2}$. Thus, cycloadduct 108 was obtained as the sole product in $98 \%$ yield under Lewis acidic conditions, whereas standard conditions provided the alternative diastereomer as the major compound (Scheme 15). ${ }^{34}$

\subsection{Synthetic Applications}

As expected, cycloadducts can be cleaved under reductive conditions. A short synthesis of (-)-monatin 111 has been reported in this manner (Scheme 16). ${ }^{33}$

The chiral appendage can also be removed under non-reductive conditions using molybdenum hexacarbonyl. This
Table 10 Cycloaddition of Nitrone with Substituted Styrenes<smiles>O=C1C=[N+]([O-])[C@H](c2ccccc2)CO1</smiles><smiles>O=C1OC[C@H](c2ccccc2)N2O[C@H](Br)[C@H]1[C@H]2Br</smiles>

\begin{tabular}{|c|c|c|c|c|}
\hline Entry & Alkene & exolendo & Combined yield $(\%)$ & Compd \\
\hline 1 & & $10: 1$ & 73 & 101 \\
\hline 2 & & $10: 1$ & 71 & 102 \\
\hline 3 & & $7: 1$ & 85 & 103 \\
\hline 4 & & $>20: 1$ & 49 & 104 \\
\hline 5 & & $5: 1$ & 55 & 105 \\
\hline 6 & & $5: 1$ & 84 & 106 \\
\hline 7 & & $10: 1$ & 70 & 107 \\
\hline
\end{tabular}<smiles>C=C(CO)Cc1c[nH]c2ccccc12</smiles>

Scheme 15 Lewis acid vs. thermal activation of nitrone cycloadditions.

procedure enables the removal of the morpholinone in substrates bearing unsaturation (Scheme 17). ${ }^{32}$

\section{$4 \quad$ Azomethine Imines}

Although less studied than azometine ylides or nitrones, azomethine imine ylides have been known since the late 1960 s to be excellent reagents in 1,3-dipolar cycloaddi- 


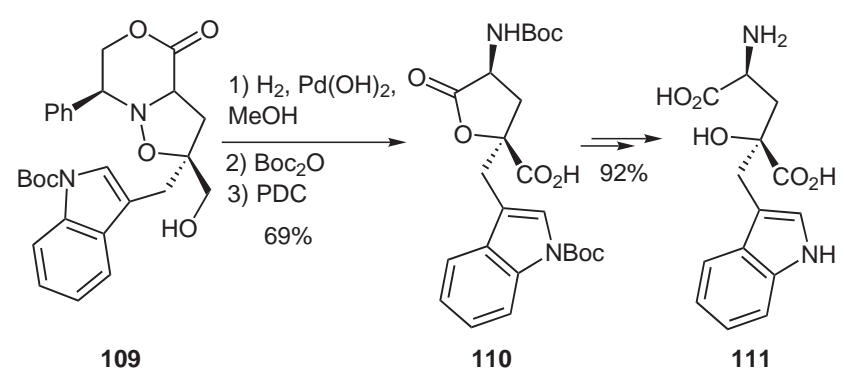

Scheme 16 Stereoselective synthesis of monatin.

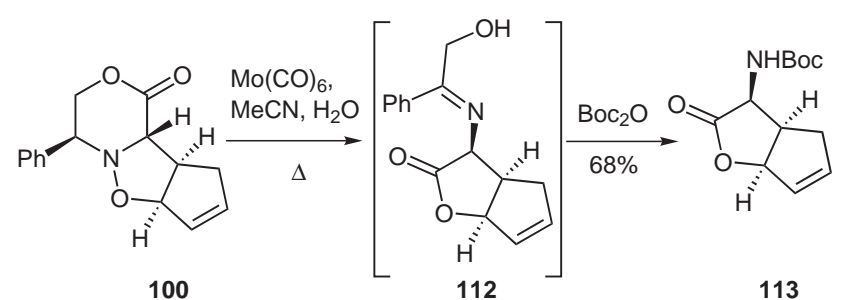

Scheme 17 Non-reductive cleavage of chiral appendage.

tions. ${ }^{35}$ Furthermore, very exciting results had been reported in stereoselective cycloadditions of five-membered racemic azomethine imines by the group of Stanovnik. ${ }^{36}$ We started to investigate the use of cyclic carbazate $\mathbf{1 1 8}$ in similar reactions in 1998.

Although the synthesis of a closely related compound in the ephedrine series had been reported by Trepanier, ${ }^{37}$ we redesigned this original route slightly in order to obtain the ylide precursor in an improved and reproducible yield (Scheme 18). The reduction step of the nitrosoamine $\mathbf{1 1 5}^{38}$ proved to be particularly difficult to optimize. We finally found that when conducted with an internal temperature maintained between $-10{ }^{\circ} \mathrm{C}$ and $0{ }^{\circ} \mathrm{C}$, the strongly exothermic LAH reduction could lead to the corresponding crystallized hydrazine in a reproducible $84 \%$ yield on medium scale (10-15 g). The same experimental procedure was conducted twice at a $100-\mathrm{g}$-scale, leading to the same product in $69 \%$ yield. ${ }^{39}$ The two final steps have also been performed on a relatively large scale $(20 \mathrm{~g})$, although some reduction problems can occur if traces of imidazole are not carefully removed after the cyclization step. Compound $\mathbf{1 1 8}$ is a stable, crystalline compound that can be obtained in five steps from $(R)-(-)$ phenylglycinol on a multigram scale, without any chromatographic purification. ${ }^{40}$

\section{1 Ylide Generation}

Attempts to generate the ylide from formaldehyde led to very inconsistent results. ${ }^{41}$ On the contrary, numerous ylides could be prepared from various aldehydes, either in a direct manner by condensation under dehydrating conditions or from the corresponding acetal under acid catalysis, or indirectly by a cycloreversion process (Scheme 19). The ylides proved to be much less stable than the crystalline compounds described in the five-

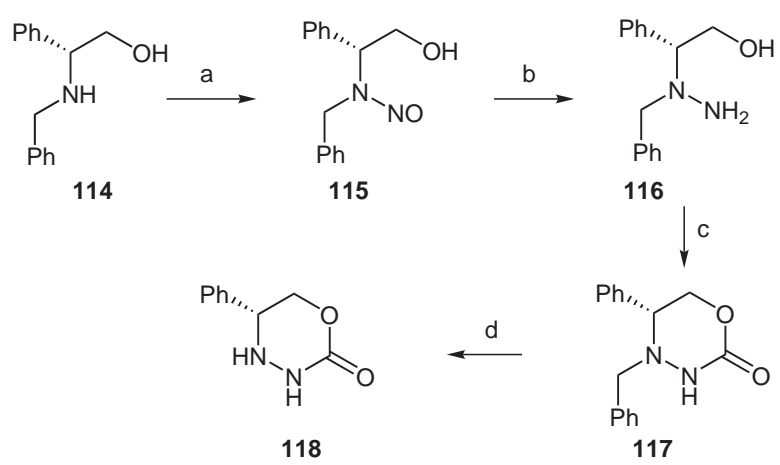

Scheme 18 Reagents and conditions: a) $\mathrm{NaNO}_{2}, \mathrm{H}_{2} \mathrm{O}-\mathrm{HCl}, 70{ }^{\circ} \mathrm{C}$, $92 \%$; b) $\mathrm{LiAlH}_{4}, \mathrm{Et}_{2} \mathrm{O},-78{ }^{\circ} \mathrm{C}$ to $-10{ }^{\circ} \mathrm{C}, 84 \%$; c) $\mathrm{Im}_{2} \mathrm{CO}, \mathrm{CH}_{2} \mathrm{Cl}_{2}$, r.t., $74 \%$; d) $\mathrm{H}_{2}, \mathrm{Pd}(\mathrm{OH})_{2}, 10$ bar, $\mathrm{MeOH}, 97 \%$.

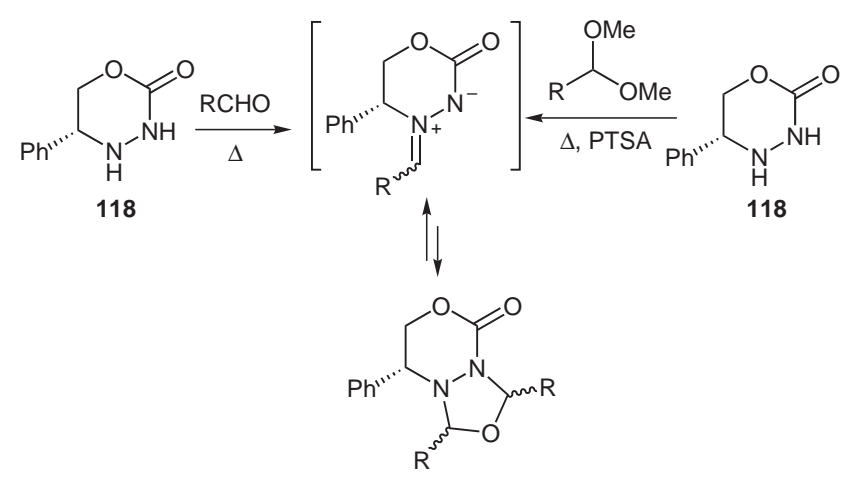

Scheme 19 Azomethine imine ylides generation.

membered series, and were not isolated prior to the cycloaddition step.

\subsection{Reactions Involving Ylides Derived from Al- iphatic or Aromatic Aldehydes}

\subsubsection{Reactions with Alkynes}

As in the azomethine series, only one cycloadduct could be obtained with diethylacetylene dicarboxylate. ${ }^{42}$ The reaction had to be performed in a stepwise manner, using the acid-catalyzed transacetalization process to avoid the competitive formation of the Michael-type direct addition of the carbazate onto the dipolarophile. The cycloadduct is air-stable when properly recrystallized, whereas its oily form rapidly oxidized to pyrazoline $\mathbf{1 2 0}$ (Scheme 20).

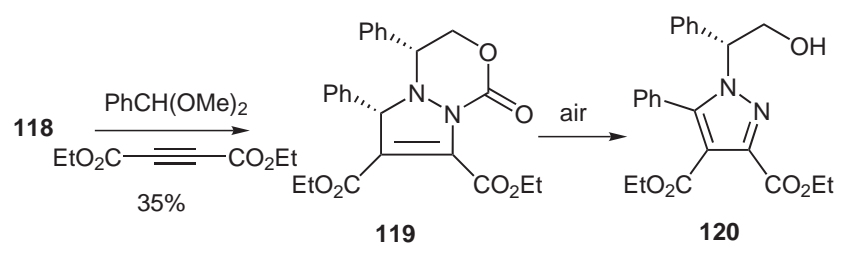

Scheme 20 Cycloadditions with activated alkynes.

\subsubsection{Reactions with Alkenes}

Carbazate-derived ylides reacted with a wide range of dipolarophiles (Table 11). ${ }^{43}$ In all the cases, the facial 'ster- 
Table 11 Cycloaddition of Azomethine Imines

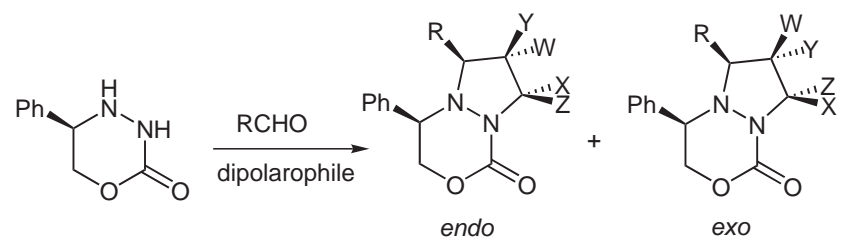

\begin{tabular}{|c|c|c|c|c|c|c|c|c|c|}
\hline \multirow[t]{2}{*}{ Entry $^{a}$} & \multirow[t]{2}{*}{$\mathrm{R}$} & \multirow[t]{2}{*}{ Dipolarophile } & \multicolumn{4}{|l|}{ Adduct } & \multirow[t]{2}{*}{ endolexo } & \multirow[t]{2}{*}{ Yield (\%) } & \multirow[t]{2}{*}{ Compd } \\
\hline & & & $\mathrm{W}$ & $X$ & $\mathrm{Y}$ & $\mathrm{Z}$ & & & \\
\hline 1 & $\mathrm{Ph}$ & $\mathrm{MeO}_{2} \mathrm{C}$ & $\mathrm{CO}_{2} \mathrm{Me}$ & $\mathrm{CO}_{2} \mathrm{Me}$ & $\mathrm{H}$ & $\mathrm{H}$ & $>99: 1$ & 63 & 121 \\
\hline 2 & $\mathrm{Ph}$ & $\mathrm{MeO}_{2} \mathrm{C}$ & $\mathrm{CO}_{2} \mathrm{Me}$ & $\mathrm{H}$ & $\mathrm{H}$ & $\mathrm{CO}_{2} \mathrm{Me}$ & $73: 27$ & 82 & 122 \\
\hline 3 & $\mathrm{Ph}$ & & $\mathrm{CO}_{2} \mathrm{Me}$ & $\mathrm{H}$ & $\mathrm{H}$ & $\mathrm{H}$ & $>99: 1$ & 74 & 123 \\
\hline 4 & $\mathrm{Ph}$ & $\mathrm{Ph}$ & $\mathrm{CO}_{2} \mathrm{Me}$ & $\mathrm{H}$ & $\mathrm{H}$ & $\mathrm{Ph}$ & $96: 4$ & 40 & 124 \\
\hline 5 & $\mathrm{Ph}$ & $\mathrm{Ph}$ & $\mathrm{H}$ & $\mathrm{Ph}$ & $\mathrm{H}$ & $\mathrm{H}$ & $14: 86$ & 48 & 125 \\
\hline 6 & $\mathrm{Ph}$ & $\mathrm{C}_{6} \mathrm{H}_{13}$ & $\mathrm{H}$ & $\mathrm{C}_{6} \mathrm{H}_{13}$ & $\mathrm{H}$ & $\mathrm{H}$ & $<1: 99$ & 50 & 126 \\
\hline 7 & 3-Pyr & $\mathrm{MeO}_{2} \mathrm{C}$ & $\mathrm{CO}_{2} \mathrm{Me}$ & $\mathrm{CO}_{2} \mathrm{Me}$ & $\mathrm{H}$ & $\mathrm{H}$ & $>99: 1$ & 69 & 127 \\
\hline 8 & 3-Pyr & $\mathrm{MeO}_{2} \mathrm{C}$ & $\mathrm{CO}_{2} \mathrm{Me}$ & $\mathrm{H}$ & $\mathrm{H}$ & $\mathrm{CO}_{2} \mathrm{Me}$ & $85: 15$ & 80 & 128 \\
\hline 9 & 3-Pyr & $\mathrm{Ph}$ & $\mathrm{H}$ & $\mathrm{Ph}$ & $\mathrm{H}$ & $\mathrm{H}$ & $15: 85$ & 78 & 129 \\
\hline 10 & 3-Pyr & $=$ & $\mathrm{CO}_{2} \mathrm{Me}$ & $\mathrm{H}$ & $\mathrm{H}$ & $\mathrm{H}$ & $>99: 1$ & 78 & 130 \\
\hline 11 & $\operatorname{Pr}$ & $\mathrm{MeO}_{2} \mathrm{C}$ & $\mathrm{CO}_{2} \mathrm{Me}$ & $\mathrm{CO}_{2} \mathrm{Me}$ & $\mathrm{H}$ & $\mathrm{H}$ & $>98: 2$ & 27 & 131 \\
\hline 12 & $\operatorname{Pr}$ & $=\mathrm{CO}_{2 \mathrm{Me}}$ & $\mathrm{CO}_{2} \mathrm{Me}$ & $\mathrm{H}$ & $\mathrm{H}$ & $\mathrm{H}$ & $65: 35$ & 62 & 132 \\
\hline 13 & $\operatorname{Pr}$ & $\mathrm{Ph}$ & $\mathrm{H}$ & $\mathrm{Ph}$ & $\mathrm{H}$ & $\mathrm{H}$ & $65: 35$ & 11 & 133 \\
\hline
\end{tabular}

${ }^{\text {a }}$ Reagents and conditions: $\mathrm{RCHO}$ (1.2-5 equiv), dipolarophile (2-4 equiv) refluxing $\mathrm{CHCl}_{3}$ or DCE.

ic' selectivity was fully controlled. The cycloaddition was generally endo-selective with dipolarophiles bearing electron-withdrawing groups, and fully stereospecific (entries $1,2,4,7,8)$. Singly activated dipolarophiles also reacted in a totally regioselective manner (entries 3, 4 and 10). Interestingly, styrene and the even less activated octene reacted with the ylide, in an exo-mode and in a regioselective manner. Although the general behavior of the azomethine imine ylide was quite similar to the reactivity of the corresponding azomethine ylide, no reaction could be observed with maleimide derivatives.

With butyraldehyde-derived ylides, the endo/exo ratio was also generally lower than in the aromatic series. Furthermore, cycloadducts were obtained in lower yields, as a result of a formal head-to-tail dimerization of the transient ylide, followed by a non-concerted ring-opening and intramolecular prototropy (Scheme 21).

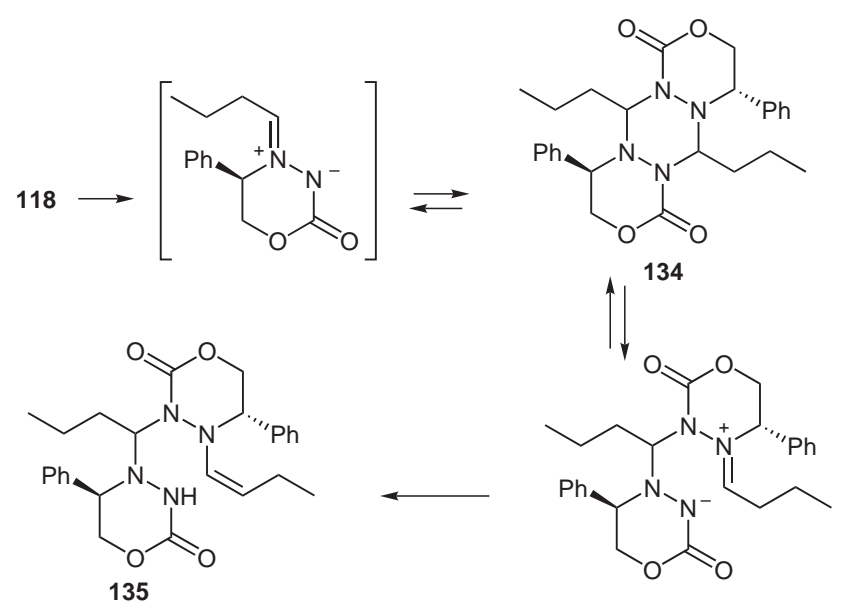

Scheme 21 Competitive degradation pathway of alkyl-based azomethine imines. 
Table 12 Tandem Cycloreversion-Cycloaddition Process

\begin{tabular}{|c|c|c|c|c|c|c|c|c|c|c|}
\hline \multirow[t]{2}{*}{ Entry } & \multirow[t]{2}{*}{$\mathrm{R}$} & \multirow[t]{2}{*}{$136(\%, \mathrm{dr})$} & \multirow[t]{2}{*}{ Dipolarophile } & \multirow{2}{*}{$\begin{array}{l}\text { Adduct } \\
\text { W }\end{array}$} & \multirow[b]{2}{*}{$X$} & \multirow[b]{2}{*}{$\mathrm{Y}$} & \multirow[b]{2}{*}{$\mathrm{Z}$} & \multirow[t]{2}{*}{ endolexo } & \multirow[t]{2}{*}{ Yield (\%) } & \multirow[t]{2}{*}{ Compd } \\
\hline & & & & & & & & & & \\
\hline 1 & $\operatorname{Pr}$ & $97,>98: 2$ & $\mathrm{MeO}_{2} \mathrm{C}$ & $\mathrm{CO}_{2} \mathrm{Me}$ & $\mathrm{CO}_{2} \mathrm{Me}$ & $\mathrm{H}$ & $\mathrm{H}$ & $>98: 2$ & 71 & 131 \\
\hline 2 & $\operatorname{Pr}$ & $97,>98: 2$ & $\mathrm{MeO}_{2} \mathrm{C}$ & $\mathrm{CO}_{2} \mathrm{Me}$ & $\mathrm{H}$ & $\mathrm{H}$ & $\mathrm{CO}_{2} \mathrm{Me}$ & $95: 5$ & 54 & 137 \\
\hline 3 & $\operatorname{Pr}$ & $97,>98: 2$ & $\mathrm{Me}$ & $\mathrm{CO}_{2} \mathrm{Me}$ & $\mathrm{H}$ & $\mathrm{H}$ & $\mathrm{Me}$ & $88: 12$ & 40 & 138 \\
\hline 4 & $\operatorname{Pr}$ & $97,>98: 2$ & $=\mathrm{CO}_{2 \mathrm{Me}}$ & $\mathrm{CO}_{2} \mathrm{Me}$ & $\mathrm{H}$ & $\mathrm{H}$ & $\mathrm{H}$ & $65: 35$ & 38 & 132 \\
\hline 5 & $\mathrm{Ph}\left(\mathrm{CH}_{2}\right)_{2}$ & 80, 70:20:10 & $\mathrm{MeO}_{2} \mathrm{C}$ & $\mathrm{CO}_{2} \mathrm{Me}$ & $\mathrm{CO}_{2} \mathrm{Me}$ & $\mathrm{H}$ & $\mathrm{H}$ & $>98: 2$ & 89 & 139 \\
\hline 6 & $\mathrm{Ph}\left(\mathrm{CH}_{2}\right)_{2}$ & $80,70: 20: 10$ & $\mathrm{MeO}_{2} \mathrm{C}$ & $\mathrm{CO}_{2} \mathrm{Me}$ & $\mathrm{H}$ & $\mathrm{H}$ & $\mathrm{CO}_{2} \mathrm{Me}$ & $89: 11$ & 85 & 140 \\
\hline 7 & $\mathrm{Ph}\left(\mathrm{CH}_{2}\right)_{2}$ & $80,70: 20: 10$ & & $\mathrm{CO}_{2} \mathrm{Me}$ & $\mathrm{H}$ & $\mathrm{H}$ & $\mathrm{Me}$ & $84: 16$ & 73 & 141 \\
\hline
\end{tabular}

This troublesome side reaction can be avoided by playing with the cycloaddition-cycloreversion equilibrium (Table 12).${ }^{44}$ Although this equilibrium is strongly shifted toward the oxadiazolidine $\mathbf{1 3 6}$ (which is the only species detectable by NMR in solution), it should be displaced by the irreversible reaction of the ylide with a dipolarophile.

This process, delivering only a very small amount of dipole in solution, should lower the above-mentioned dimerization side reaction. A general yield improvement could be observed using this procedure, except with methylacrylate. ${ }^{45}$ The stereochemical outcome of the tandem cycloreversion-cycloaddition pathway was similar to the direct one-pot procedure, showing that the reactive intermediates were identical.

\subsection{Reactions Involving Ylides Derived from Alkyl Glyoxylates}

All attempts to use alkylglyoxalates in a direct cycloaddition from carbazate $\mathbf{1 1 8}$ were unsuccessful. The cycloreversion route was therefore investigated, but the formation of oxadiazolidine $\mathbf{1 4 2}$ was problematic. While thermal or acidic activation failed, we were pleased to see that a diastereomeric mixture of $\mathbf{1 4 2}$ could be obtained in a good yield when the condensation was performed in the presence of magnesium bromide etherate (Scheme 22).

This diastereomeric mixture reacted with a wide range of dipolarophiles, leading to the corresponding cycloadducts

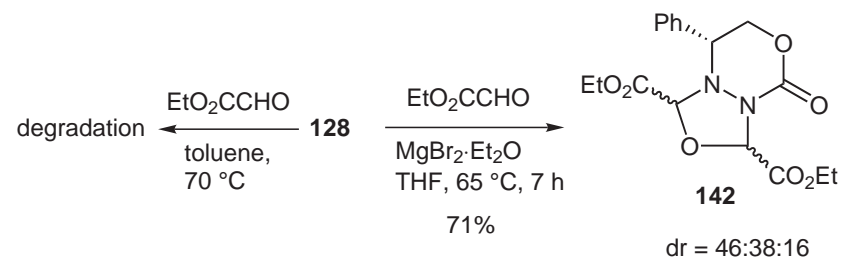

Scheme 22 Oxadiazolidine synthesis.

in generally good chemical yields (Table 13). ${ }^{46}$ As in the azomethine ylide series, the exo proportion of adducts increased (entries 1-4), and was almost exclusive with 'non-activated' alkenes (entries 5-7). For the first time in this series, a cycloadduct could be obtained with $N$-phenylmaleimide as a dipolarophile.

\subsection{Synthetic Applications}

As in the azomethine ylide series, cleavage of the chiral appendage can be performed under hydrogenolytic conditions. This step was particularly difficult to optimize. The nature of the acidic co-catalyst proved to be crucial, since the use of $6 \mathrm{~N}$ aqueous hydrochloric acid instead of concentrated sulfuric acid led to compound 143 in a non-reproducible low yield, and no reaction could be obtained with trifluoroacetic acid (Scheme 23). Only starting material was recovered when performing the hydrogenolysis without any acidic co-catalyst or substoichiometric quantities of sulfuric acid. The change of palladium hydroxide 
Table 13 Tandem Cycloreversion-Cycloaddition Process

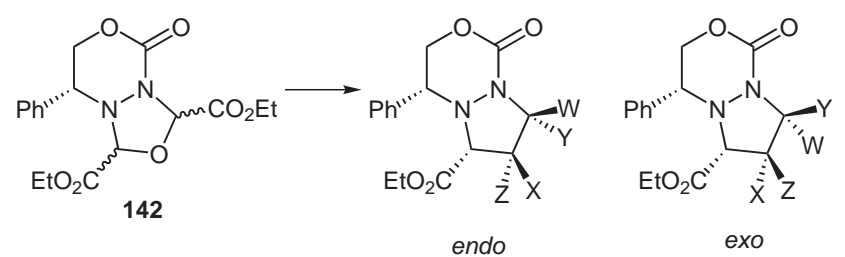

\begin{tabular}{|c|c|c|c|c|c|c|}
\hline Entry & W & $\mathrm{X}$ & $\mathrm{Y}$ & $\mathrm{Z}$ & endolexo & Yield (\%) \\
\hline 1 & $\mathrm{CO}_{2} \mathrm{Et}$ & $\mathrm{CO}_{2} \mathrm{Et}$ & $\mathrm{H}$ & $\mathrm{H}$ & $85: 15$ & 84 \\
\hline 2 & $\mathrm{CO}_{2} \mathrm{Et}$ & $\mathrm{H}$ & $\mathrm{H}$ & $\mathrm{CO}_{2} \mathrm{Et}$ & $66: 36$ & 71 \\
\hline 3 & $(\mathrm{CO}) \mathrm{NPh}(\mathrm{CO})$ & & $\mathrm{H}$ & $\mathrm{H}$ & $75: 25$ & 73 \\
\hline 4 & $\mathrm{H}$ & $\mathrm{CO}_{2} \mathrm{Me}$ & $\mathrm{Me}$ & $\mathrm{H}$ & $59: 41$ & 71 \\
\hline 5 & $\mathrm{Ph}$ & $\mathrm{H}$ & $\mathrm{H}$ & $\mathrm{H}$ & $5: 95$ & 48 \\
\hline 6 & $p-\mathrm{MeOC}_{6} \mathrm{H}_{4}$ & $\mathrm{H}$ & $\mathrm{H}$ & $\mathrm{H}$ & $3: 97$ & 51 \\
\hline 7 & $p-\mathrm{MeO}_{2} \mathrm{CC}_{6} \mathrm{H}_{4}$ & $\mathrm{H}$ & $\mathrm{H}$ & $\mathrm{H}$ & $7: 93$ & 65 \\
\hline
\end{tabular}

for platinum as a catalyst led to the reduction product without hydrogenolysis or $\mathrm{N}-\mathrm{N}$ bond cleavage. Finally, best results were obtained when the hydrogenolysis was performed with Pearlman's catalyst in methanol in the presence of three equivalents of concentrated sulfuric acid. The resulting pyrrazolidines had to be protected as bisbenzamides, in order to avoid a rapid oxidation to the corresponding hydrazones.

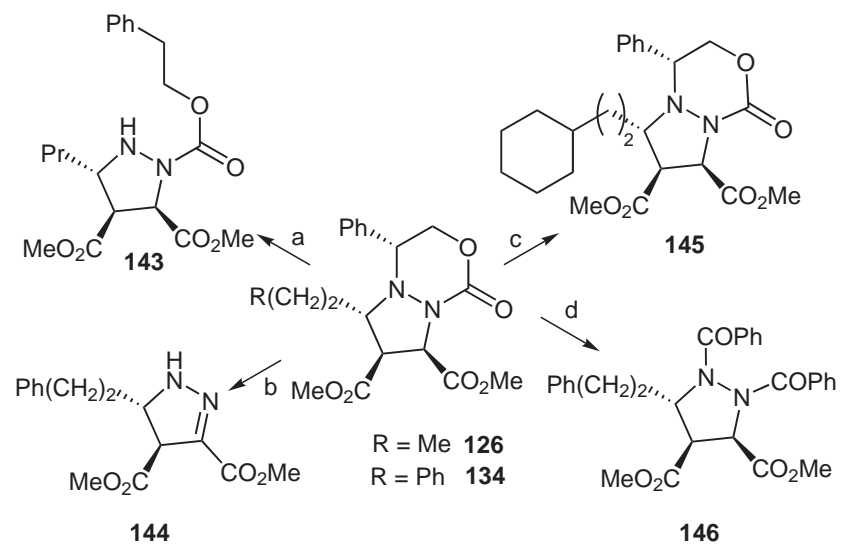

Scheme 23 Reagents and conditions: (a) $(\mathrm{R}=\mathrm{Me}) \mathrm{H}_{2}, \mathrm{Pd}(\mathrm{OH})_{2}$, $\mathrm{MeOH}, 6 \mathrm{~N}$ aq HCl, 25\%; (b) $(\mathrm{R}=\mathrm{Ph})\left(\right.$ i) $\mathrm{H}_{2}, \mathrm{Pd}(\mathrm{OH})_{2}, \mathrm{MeOH}$, $\mathrm{H}_{2} \mathrm{SO}_{4}$ (3 equiv); (ii) silica gel, $29 \%$; (c) $(\mathrm{R}=\mathrm{Ph}) \mathrm{H}_{2}, \mathrm{Pt}$ black, $\mathrm{MeOH}, \mathrm{H}_{2} \mathrm{SO}_{4}$ (1 equiv), $19 \%$; d) $(\mathrm{R}=\mathrm{Ph})\left(\right.$ i) $\mathrm{H}_{2}, \mathrm{Pd}(\mathrm{OH})_{2}, \mathrm{MeOH}$, $\mathrm{H}_{2} \mathrm{SO}_{4}$ (2 equiv); (ii) $\mathrm{PhCOCl}$ (5.5 equiv), $\mathrm{DBU}$ (3 equiv), $\mathrm{CH}_{2} \mathrm{Cl}_{2}$, $79 \%, \mathrm{dr}>98: 2$.

This procedure enabled the preparation of a range of protected pyrrazolidines without any racemization (Figure 2).

Despite extensive investigations, all hydrogenolyses performed on cycloadducts bearing two benzylic positions led exclusively to the cleavage of the five-membered ring. Not only pyrrazolidines, but also diamines can be obtained from azomethine imine cycloadditions after reduc-

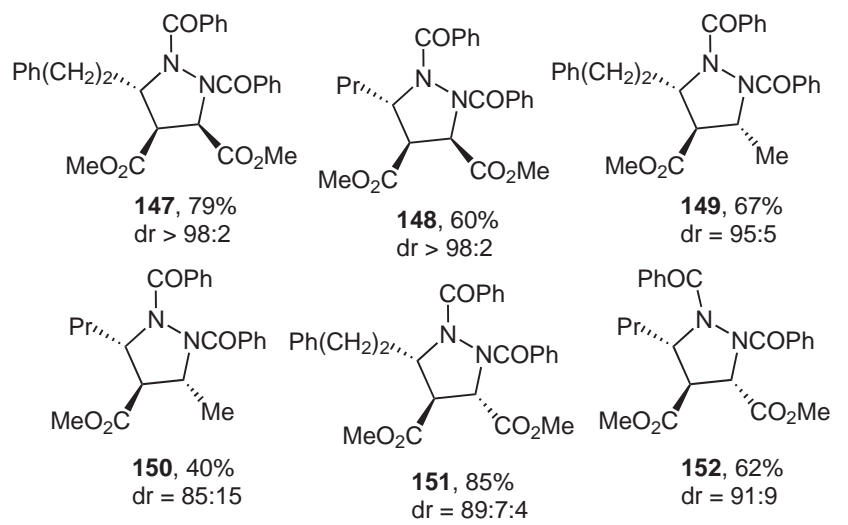

Figure 2 Synthesis of protected functionalized pyrrazolidines.

tive cleavage of the $\mathrm{N}-\mathrm{N}$ bond. Although several procedures have been described for this transformation, they proved to be unsuitable on our densely functionalized substrates. The use of Raney nickel, for instance, enabled the one-pot reduction of the hydrazine bond and the removal of the chiral appendage, but led to the formation of amino pyrrolidinone $\mathbf{1 5 3}$ as the result of the lactamization of the transient amino ester (Scheme 24).

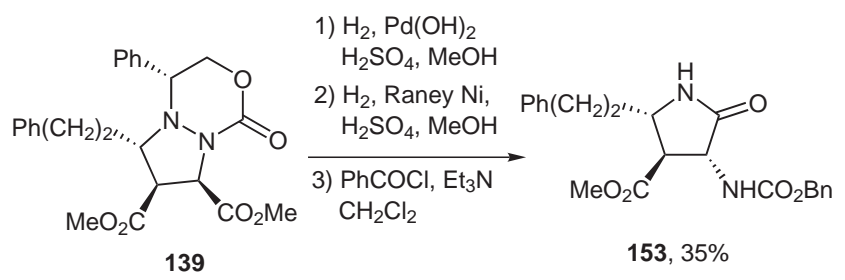

Scheme 24 Synthesis of fucntionnalized pyrrolidinones.

We finally found that pyrrazolidinones $\mathbf{1 5 4}-\mathbf{1 5 9}$ could be cleanly reduced electrochemically, leading to the desired final diamides with very little epimerization of sensitive centers, provided that the reduction was conducted under carefully buffered neutral $\mathrm{pH}$ (Table 14). ${ }^{47}$ 
Table 14 Electrochemical N-N Bond Cleavage

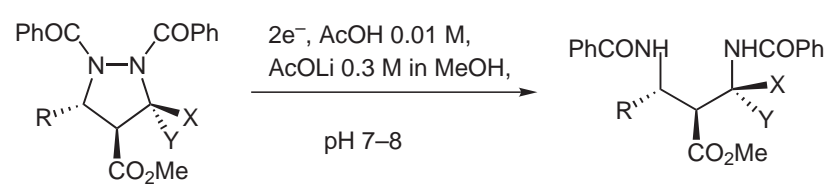

\begin{tabular}{|c|c|c|c|c|c|c|}
\hline Entry & $\mathrm{R}$ & $X$ & $\mathrm{Y}$ & $\mathrm{dr}$ & Yield (\%) & Compd \\
\hline 1 & $\mathrm{Ph}\left(\mathrm{CH}_{2}\right)_{2}$ & $\mathrm{CO}_{2} \mathrm{Me}$ & $\mathrm{H}$ & $96: 4$ & 65 & 154 \\
\hline 2 & $\mathrm{Ph}\left(\mathrm{CH}_{2}\right)_{2}$ & $\mathrm{H}$ & $\mathrm{CO}_{2} \mathrm{Me}$ & $>98: 2$ & 73 & 155 \\
\hline 3 & $\mathrm{Ph}\left(\mathrm{CH}_{2}\right)_{2}$ & $\mathrm{H}$ & $\mathrm{Me}$ & $97: 3$ & 71 & 156 \\
\hline 4 & $\operatorname{Pr}$ & $\mathrm{CO}_{2} \mathrm{Me}$ & $\mathrm{H}$ & $97: 3$ & 90 & 157 \\
\hline 5 & $\operatorname{Pr}$ & $\mathrm{H}$ & $\mathrm{CO}_{2} \mathrm{Me}$ & $95: 5$ & 80 & 158 \\
\hline 6 & $\operatorname{Pr}$ & $\mathrm{H}$ & $\mathrm{Me}$ & $97: 3$ & 69 & 159 \\
\hline
\end{tabular}

\section{$5 \quad$ Conclusion}

This general survey clearly highlights the great synthetic potential of cyclic ylides derived from chiral amino alcohols. They can lead, by simple experimental manipulation, to a wide range of interesting structures with a great functional, regio- and stereodiversity, in a predictable manner. Despite their apparent structural similarities, leading to an identical 'steric' control of the cycloaddition process, the three classes of ylides exhibited different reactivity patterns. Azomethine ylides generally react under thermal activation with electron-deficient alkenes (preferably doubly activated) mainly in an endo manner, and poorly with dipolarophiles bearing neutral or electron-donating groups. On the contrary, nitrones give excellent results with electron-rich alkenes, leading mainly to exo adducts. Azomethine imine ylides exhibit an intermediate reactivity, leading to endo adducts with electron-deficient dipolarophiles and exo derivatives with non-activated alkenes. These different reactivities, with structurally very similar systems, clearly outline the importance of electronic effects and orbital control in dipolar cycloadditions. Thus, according to the Sustmann classification (Figure 3 ) ${ }^{48}$ azomethine ylides behave as type 1 dipoles, leading to reactions with a predominant $\mathrm{HOMO}_{\text {dipole }}{ }^{-}$ $\mathrm{LUMO}_{\text {dipolarophile }}$ control, whereas nitrones react as type 3 dipoles by a $\mathrm{LUMO}_{\text {dipole }}-\mathrm{HOMO}_{\text {dipolarophile }}$ pathway.

The reactivity of azomethine imines is more typical for a type 2 dipole, with the cycloaddition being mainly governed by the level of the dipolarophile's FMOs. It can therefore be expected that such ylide, able to react with almost all kinds of dipolarophiles in a predictable manner, will be an excellent tool for a rapid generation of functionally and stereochemically diverse molecules.

\section{Acknowledgment}

Prof. H.-P. Husson is acknowledged for his interest in this work. We thank Prof. L. M. Harwood for a critical reading of this manuscript.

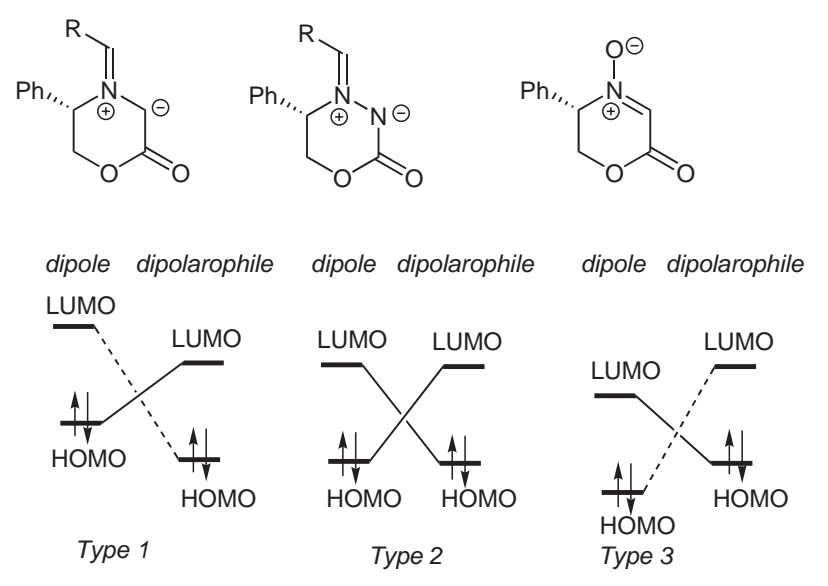

Figure 3

\section{References and Notes}

(1) (a) Multicomponent Reactions; Zhu, J.; Bienaymé, H., Eds.; Wiley-VCH: Weinheim, 2005. (b) Ulaczyk-Lesanko, A.; Hall, D. G. Curr. Opin. Chem. Biol. 2005, 9, 2666. (c) Zhu, J. Eur. J. Org. Chem. 2003, 1133. (d) Bienaymé, H.; Hulme, C.; Odon, G.; Schmidt, P. Chemistry 2000, 6, 3321.

(2) (a) Karlsson, S.; Högberg, H.-E. Org. Prep. Proced. Int. 2001, 33, 105. (b) Gothelf, K. V.; Jørgensen, K. A. Chem. Rev. 1998, 98, 863.

(3) For a general review on asymmetric multicomponent reactions, see: Ramón, D. J.; Yus, M. Angew. Chem. Int. Ed. 2005, 44, 1602.

(4) Schreiber, S. L. Science 2000, 287, 1964.

(5) (a) Bournaud, C.; Robic, D.; Bonin, M.; Micouin, L. J. Org. Chem. 2005, 70, 3316. (b) Pérez Luna, A.; Cesario, M.; Bonin, M.; Micouin, L. Org. Lett. 2003, 5, 4771. (c) Pérez Luna, A.; Bonin, M.; Micouin, L.; Husson, H.-P. J. Am. Chem. Soc. 2002, 124, 12098. (d) Pérez Luna, A.; Ceschi, M.-A.; Bonin, M.; Micouin, L.; Husson, H.-P.; Gougeon, S.; Estenne-Bouhtou, G.; Marabout, B.; Sevrin, M.; George, P. J. Org. Chem. 2002, 67, 3522.

(6) For an excellent recent review on azomethine ylides, see: Nájera, C.; Sansano, J. M. Curr. Org. Chem. 2003, 7, 1105.

(7) For a general review on cycloadditions with nitrones, see: Confalone, P. N.; Huie, E. M. Org. React. 1988, 36, 1. 
(8) Asymmetric hydrogenations: (a) Vigneron, J. P.; Kagan, H. B.; Horeau, A. Tetrahedron Lett. 1968, 9, 5681.

(b) Vigneron, J. P.; Kagan, H. B.; Horeau, A. Bull. Soc. Chim. Fr. 1972, 3836. (c) The use of morpholinones for the stereoselective formation of $\mathrm{C}-\mathrm{C}$ bonds had also been reported later: Dellaria, J. F. Jr.; Santarsiero, B. D. J. Org. Chem. 1989, 54, 3916.

(9) (a) Anslow, A. S.; Harwood, L. M.; Phillips, H.; Watkin, D. Tetrahedron : Asymmetry 1991, 2, 169. (b) Chinchilla, R.; Falvello, L. R.; Galindo, N.; Nájera, C. Eur. J. Org. Chem. 2001, 3133.

(10) (a) Williams, R. M.; Zhai, W.; Aldous, D. J.; Aldous, S. C. J. Org. Chem. 1992, 57, 6527. (b) With a preliminary description in the first chapter of: (c) Williams, R. M. In Synthesis of Optically a-Amino Acids; Pergamon Press: Oxford, 1989, 113.

(11) Alker, D.; Harwood, L. M.; Williams, C. E. Tetrahedron 1997, 53, 12671.

(12) Aldous, D. J.; Hamelin, E. M.-N.; Harwood, L. M.; Thurairatnam, S. Synlett 2001, 1841.

(13) Anslow, A. S.; Harwood, L. M.; Phillips, H.; Watkin, D.; Wong, L. F. Tetrahedron: Asymmetry 1991, 2, 1343.

(14) Harwood, L. M.; Manage, A. C.; Robin, S.; Hopes, S. F. G.; Watkin, D. J.; Williams, C. E. Synlett 1993, 777.

(15) Anslow, A. S.; Harwood, L. M.; Phillips, H.; Watkin, D. Tetrahedron: Asymmetry 1991, 2, 997.

(16) Baldwin, J. E.; MacKenzie Turner, S. C.; Moloney, M. G. Synlett 1994, 925

(17) Sebahar, P. R.; Williams, R. M. Heterocycles 2002, 58, 563.

(18) Harwood, L. M.; Macro, J.; Watkin, D.; Williams, C. E.; Wong, L. F. Tetrahedron: Asymmetry 1992, 3, 1127.

(19) Alker, D.; Hamblett, G.; Harwood, L. M.; Robertson, S. M.; Watkin, D. J.; Williams, C. E. Tetrahedron 1998, 54, 6089.

(20) Alker, D.; Harwood, L. M.; Williams, C. E. Tetrahedron Lett. 1998, 39, 475.

(21) Harwood, L. M.; Lilley, I. A. Tetrahedron: Asymmetry 1995, 6, 1557.

(22) Aldous, D. J.; Drew, M. G. B.; Hamelin, E. M.-N.; Harwood, L. M.; Jahans, A. B.; Thurairatnam, S. Synlett 2001, 1836.

(23) Aldous, D. J.; Drew, M. G. B.; Draffin, W. N.; Hamelin, E. M.-N.; Harwood, L. M.; Thurairatnam, S. Synthesis 2005, 3271.

(24) The same side reaction has been observed by Harwood and co-workers, see ref. 19

(25) Spirotryprostatin B: (a) Sebahar, P. R.; Williams, R. M. J. Am. Chem. Soc. 2000, 122, 5666. (b) Sebahar, P. R.; Osada, H.; Usui, T.; Williams, R. M. Tetrahedron 2002, 58, 6311. (c) Spirotryprostatin A: Onishi, T.; Sebahar, P. R.; Williams, R. M. Org. Lett. 2003, 5, 3135.

(26) Ahrendt, K. A.; Williams, R. M. Org. Lett. 2004, 6, 4539.

(27) (a) Chen, C.; Li, X.; Neumann, C. S.; Lo, M. M.-C.; Schreiber, S. L. Angew. Chem. Int. Ed. 2005, 44, 2249. (b) Lo, M. M.-C.; Neumann, C. S.; Nagayama, S.; Perlstein, E. O.; Schreiber, S. L. J. Am. Chem. Soc. 2004, 126, 16077.
(28) Tamura, O.; Gotanda, K.; Terashima, R.; Kikuchi, M.; Miyawaki, T.; Sakamoto, M. Chem. Commun. 1996, 1861.

(29) Baldwin, S. W.; Young, B. G.; McPhail, A. T. Tetrahedron Lett. 1998, 39, 6819.

(30) (a) Murray, R.; Iyanar, K. J. Org. Chem. 1996, 61, 8099. (b) Gotti, A.; Nanelli, L. Tetrahedron Lett. 1996, 37, 6025.

(31) Despite a longer synthetic pathway, the hydroxylamine route delivers the nitrone as a crystalline material, whereas the product coming from the direct oxidation of the morpholinone has been described as an orange oil, see ref. 28 and 29.

(32) Tamura, O.; Gotanda, K.; Yoshino, J.; Morita, Y.; Terashima, R.; Kikuchi, M.; Miyawaki, T.; Mita, N.; Yamashita, M.; Ishibayashi, H.; Sakamoto, M. J. Org. Chem. 2000, 65, 8544 .

(33) Long, A.; Baldwin, S. W. Tetrahedron Lett. 2001, 42, 5343.

(34) Tamura, O.; Shiro, T.; Toyao, A.; Ishibayashi, H. Chem. Commun. 2003, 2678.

(35) (a) Dorn, H.; Otto, A. Chem. Ber. 1968, 101, 3287.

(b) Oppolzer, W. Tetrahedron Lett. 1970, 15, 2199.

(c) Oppolzer, W. Tetrahedron Lett. 1972, 17, 1707.

(36) (a) Svete, J.; Preseren, A.; Stanovnik, B.; Golic, L.; GolicGrdadolnik, S. J. Heterocycl. Chem. 1997, 34, 1323.

(b) Zlicar, M.; Stanovnik, B.; Tisler, M. J. Heterocycl. Chem. 1993, 30, 1209. (c) Zlicar, M.; Stanovnik, B.; Tisler, M. Tetrahedron 1992, 48, 7965.

(37) Trepanier, D. L.; Krieger, P. E.; Eble, J. N. J. Med. Chem. 1965, 8, 802.

(38) CAUTION: Nitrosoamines are known to be highly toxic and must be handled with care.

(39) Roussi, F.; Bonin, M.; Chiaroni, A.; Micouin, L.; Riche, C.; Husson, H.-P. Tetrahedron Lett. 1998, 39, 8081.

(40) Some modifications of this route have been recently proposed, see: (a) Casper, D. M.; Kieser, D.; Blackburn, J. R.; Hitchcock, S. R. Synth. Commun. 2004, 34, 835; and references therein. (b) Rodrigues, A.; Olivato, P. R.; Rittner, R. Synthesis 2005, 2578.

(41) Roussi, F. PhD Thesis; Université René Descartes: Paris, 1999.

(42) Roussi, F.; Bonin, M.; Chiaroni, A.; Micouin, L.; Riche, C.; Husson, H.-P. Tetrahedron Lett. 1999, 40, 3727.

(43) Roussi, F.; Chauveau, A.; Bonin, M.; Micouin, L.; Husson, H.-P. Synthesis 2000, 1170.

(44) For a similar use of cycloreversion, see: Khaus, V. V.; Martinelli, M. J. Tetrahedron Lett. 1996, 37, 4323.

(45) The lower yield could be explained by the degradation of the dipolarophile during the slow cycloreversion process.

(46) Chung, F.; Chauveau, A.; Seltki, M.; Bonin, M.; Micouin, L. Tetrahedron Lett. 2004, 45, 3127.

(47) Chauveau, A.; Martens, T.; Bonin, M.; Micouin, L.; Husson, H.-P. Synthesis 2002, 1885.

(48) (a) Sustmann, R. Tetrahedron Lett. 1971, 2717. (b) Sustmann, R. Pure Appl. Chem. 1974, 40, 569. 